\title{
The role of local atmospheric forcing on the modulation of the ocean mixed layer depth in reanalysis and a coupled single column ocean model
}

Article

Accepted Version

Pookkandy, B., Dommenget, D., Klingaman, N., Wales, S., Chung, C., Frauen, C. and Wolff, H. (2016) The role of local atmospheric forcing on the modulation of the ocean mixed layer depth in reanalysis and a coupled single column ocean model. Climate Dynamics, 47 (9-10). pp. 2991-3010. ISSN 1432-0894 doi: https://doi.org/10.1007/s00382-016-3009-7 Available at https://centaur.reading.ac.uk/54534/

It is advisable to refer to the publisher's version if you intend to cite from the work. See Guidance on citing.

Published version at: http://link.springer.com/article/10.1007/s00382-016-3009-7

To link to this article DOI: http://dx.doi.org/10.1007/s00382-016-3009-7

Publisher: Springer

All outputs in CentAUR are protected by Intellectual Property Rights law, including copyright law. Copyright and IPR is retained by the creators or other copyright holders. Terms and conditions for use of this material are defined in the End User Agreement. 


\section{www.reading.ac.uk/centaur}

\section{CentAUR}

Central Archive at the University of Reading

Reading's research outputs online 
1 The role of local atmospheric forcing on the modulation of the ocean mixed layer depth in reanalyses and a coupled single column ocean model

4 Byju Pookkandy ${ }^{1}{ }^{*}$, Dietmar Dommenget ${ }^{1}$, Nicholas Klingaman ${ }^{2}$, Scott Wales ${ }^{3}$,

5 Christine Chung ${ }^{4}$, Claudia Frauen ${ }^{5}$, Holger Wolff ${ }^{1}$

6

$7 \quad{ }^{1}$ ARC Centre of Excellence for Climate System Science, School of Earth Atmosphere and

8 Environment, Monash University, Clayton, Victoria, Australia

$9{ }^{2}$ National Centre for Atmospheric Science-Climate and Department of Meteorology, University of

10 Reading, UK

$11{ }^{3}$ ARC Centre of Excellence for Climate System Science, School of Earth Sciences, The University of

12 Melbourne, Australia

$13{ }^{4}$ Bureau of Meteorology, Melbourne, Australia

$14{ }^{5}$ CNRM-GAME (Météo-France/CNRS), Toulouse, France

15

$16 *$ Corresponding author:

17 Byju Pookkandy

18 byju.pookkandy@monash.edu

19 Ph: +61-3-990-54495

20

21

22

23

24

25

26

27

28

29

30

31

32

33

34 


\section{Abstract}

36 The role of local atmospheric forcing on the ocean mixed layer depth (MLD) over the

37 global oceans is studied using ocean reanalysis data products and a single-column

38 ocean model coupled to an atmospheric general circulation model. The focus of this

39 study is on how the annual mean and the seasonal cycle of the MLD relate to various

40 forcing characteristics in different parts of the world's oceans, and how anomalous

41 variations in the monthly mean MLD relate to anomalous atmospheric forcings. By

42 analysing both ocean reanalysis data and the single-column ocean model, regions with

43 different dominant forcings and different mean and variability characteristics of the

44 MLD can be identified. Many of the global oceans' MLD characteristics appear to be

45 directly linked to the different atmospheric forcing characteristics at different

46 locations. Here, heating and wind-stress are identified as the main drivers; in some,

47 mostly coastal, regions the atmospheric salinity forcing also contributes. The annual

48 mean MLD is more closely related to the annual mean wind-stress and the MLD

49 seasonality is more closely related to the seasonality in heating. The single-column

50 ocean model, however, also points out that the MLD characteristics over most global

51 ocean regions, and in particular in the tropics and subtropics, cannot be maintained by

52 local atmospheric forcings only, but are also a result of ocean dynamics that are not

53 simulated in a single-column ocean model. Thus, lateral ocean dynamics are essential

54 in correctly simulating observed MLD.

55

56 Key words: Ocean mixed layer depth; Atmospheric forcings; Coupled single column ocean

57 model; Annual mean; Seasonal variability; Flux correction 


\section{Introduction}

70 The processes occurring in the upper ocean are predominantly forced by the atmosphere. Heating and cooling at daily to seasonal scales, wind-stress, evaporation and precipitation are the dominant physical processes that act on and interact with the upper layer of the ocean. Vigorous turbulent mixing near the surface by these forces results in a layer of homogeneous temperature and salinity (and thus density); its depth is defined as the ocean mixed layer depth (MLD).

76 Understanding the physics of the MLD is important for climate dynamics, because the thickness of the mixed layer (ML) modulates its heat capacity and hence its ability to store excess heat from the atmosphere (Godfrey and Lindstrom 1989; Maykut and McPhee 1995; Swenson and Hansen 1999; Peter et al. 2006; Dong et al. 2007; Montégut et al. 2007). In addition, MLD variations over the seasonal cycle or anomalies from it are one of the main processes for exchanging heat between the atmosphere and the deeper oceans. Proper quantification of the ML heat budget is important as it governs the evolution of the sea surface temperature (SST) (Chen et al. 1994; Alexander et al. 2000; Dommenget and Latif 2002; Qui et al. 2004; Dong et al. 2008). In a study using a simple stochastic model, Dommenget and Latif (2008) showed that the low frequency (e.g., decadal) variability in SST is a result of the interaction of the heat stored in the layers below the MLD and the heat in the mixed layer. It thus suggests that decadal SST variability strongly depends on how the MLD varies and interacts with the subsurface layers. According to them the sensitivity of SST to MLD variability maximizes in the midlatitudes. Therefore, seasonal to interannual, and maybe even decadal, variability in SST can be simulated in terms of the local air-sea interactions and proper representation of MLD variability. Mixed-layer dynamics are also important for the ocean's biological productivity (Fasham 1995; Polovina et al. 1995; Narvekar and Kumar 2006) and acts as a medium for exchange of trace gases between the ocean and the atmosphere (Takahashi et al. 1997; Bates 2001; Sabine et al. 2004).

95 A number of studies have examined the mixed layer dynamics and demonstrated the variation 96 in MLD at different spatial and temporal scales (Montery and Levitus 1997; Kara et al. 2000; 97 Cronin and Kessler 2002; Kara et al. 2003; Montégut et al. 2004; Halkides and Lee 2009). Most of these studies were limited to either a small region or at specific locations where insitu data is available, and then extrapolated over a wider domain using some specific techniques. Since the advent of Argo data, reanalysis methods have produced a much more reliable source of representations of the state of the ocean at global scale. It has been shown that in summer the MLD is dominated by entrainment due to wind-induced mixing, whereas 
103 in winter surface buoyancy forcing is the main driver (Alexander et al. 2000). These theories 104 represent generalised concepts of MLD variability in the global ocean. However, the relative 105 role of these forcings varies in time and space. This uneven distribution of MLD forcing on 106 the seasonal time scale is not understood in detail over the global ocean. Lorbacher et al. 107 (2006) and Carton et al. (2008) examined the variability in MLD at global scale from 108 observations, but these are sparse over the Southern Ocean. Numerous attempts have been 109 made to understand the ocean surface boundary layer and its sensitivity to atmospheric 110 forcing (e.g., Adamec and Elsberry 1984; Large and Crawford 1995; Kantha and Clayson 111 1994), but again they have mostly been limited to one location or in a small ocean basin.

112 The focus of the present study is to examine the mean, seasonal cycle and variability of the 113 MLD over the global ocean and how it relates to the different atmospheric forcings and the 114 upper-ocean stratification. The aim is to understand the driving mechanisms of the MLD in 115 different regions and to what extent these can be understood by the local air-sea interactions. 116 In this we will focus on open ocean regions and do not discuss sea ice regions or shallow 117 coastal ocean regions. Therefore, the MLD and the atmospheric forcing terms will be 118 analysed in ocean reanalysis data and in a single-column mixed layer ocean model coupled to 119 an atmospheric general circulation model (AGCM). The latter model simulation allows 120 insight as to what extent the MLD characteristics can be simulated just by local air-sea 121 interactions. It also allows us to diagnose the limitations of local air-sea interactions 122 assumption by analysing the flux correction terms used in the model to maintain a density 123 profile close to the observed mean profile.

124 The paper is organized as follows: A detailed description of the reanalysis data used, the 125 coupled model and the method to estimate the MLD is presented in the following section.

126 Section 3 focuses on the observed characteristics of MLD estimated from reanalysis data. In 127 section 4 most of the analysis is repeated for the single-column model simulation. Finally, the 128 results are summarised and discussed in section 5.

\section{2. Data, Model and Methods}

131 Reanalyses and data from a single-column ocean model are used to understand the 132 characteristics of the global ocean mixed layer depth and its relation to local atmospheric 133 forcing. Details of the datasets and methods used in this study are described below. 
136 The characteristics of the MLD presented here are partly based on vertical profiles of 137 temperature and salinity from the German contribution to Estimating the Circulation and 138 Climate of the Ocean system (GECCO2) for the period 1948-2011. The data has a spatial 139 resolution of $1 \times 1$ degrees in longitude and latitude and comprises 50 vertical levels. The 140 synthesis used model assimilation with available hydrographic and satellite data. A complete 141 description of this data is given by Kohl (2014). Two other data assimilation products are 142 also analysed in addition to GECCO2: The Global Ocean Data Assimilation System 143 (GODAS) data (Behringer and Xue 2004) implemented at National Centers for 144 Environmental Prediction (NCEP) for the period 1980-2013 and the Simple Ocean Data 145 Assimilation (SODA v2.2.4) data for the period 1950-2010 (Carton and Giese 2008). In the 146 following analysis we will focus all analyses on GECCO2, because it provides data for a 147 longer time period than the NCEP-GODAS dataset and compared to the SODA dataset the 148 results appear to be slightly less noisy. The reanalyses are a combination of model dynamics 149 and sparse observational data, therefore one can expect biases between the products that arise 150 from different assimilation procedures (Kröger et al. 2012). Overall the results we present in 151 this study are qualitatively the same in all three datasets. Any significant differences are 152 pointed out in the text.

153

\section{4 b. The coupled single column ocean model (ACCESS-KPP)}

155 A 50-year simulation of a coupled atmosphere-ocean single-column model is used to study 156 the MLD variability over the global ocean. The atmospheric component of the coupled model 157 consists of the Australian Community Climate and Earth-System Simulator (ACCESS) 158 version 1.3 atmospheric GCM, which is similar to the UK Met Office's Global Atmosphere version 1.0 with the addition of some modifications included by the Centre for Australian

160 Weather and Climate Research (CAWCR). A horizontal resolution of $3.75^{\circ}$ longitude by $2.5^{\circ}$ 161 latitude (referred to as N48) and 38 vertical levels are applied in this model setup. A detailed 162 description of the atmospheric model is given in Bi et al. (2013).

163 The ocean component of the coupled model consists of a single-column first-order nonlocal 164 K-Profile Parameterisation (KPP) mixed layer model, which uses the vertical mixing scheme 165 of Large et al. (1994). It comprises 40 vertical levels with the layer thickness increasing 166 exponentially from the surface to $1000 \mathrm{~m}$ deep. The single-column ocean model is coupled to 167 the atmospheric model at every ocean grid point of the atmospheric model, and at the time 168 step of both atmosphere and oceanic models (30min), following Klingaman and Woolnough 169 (2014) and Hirons et al. (2015). The KPP model is very adaptable and flexible; it can be 
applied to AGCM of any resolution. The atmospheric model provides the surface heat flux, wind-stress and freshwater flux (evaporation minus precipitation or E-P) to the ocean at each time step. The mixed layer model does not represent processes such as horizontal advection

173 or upwelling from below the limited vertical domain. Mixing in the interior (layer bellow the 174 surface) is governed by shear instability, which is modelled as a function of the local gradient

175 Richardson number. A boundary layer depth is determined at each grid point, based on the 176 critical value of the turbulent processes parameterised by a bulk Richardson number. Vertical 177 diffusivity coefficients due to turbulent shear are estimated in the diagnosed boundary layer 178 depth. Mixing is strongly enhanced in the boundary layer in both convective and wind driven 179 situations enabling boundary layer properties to penetrate well into the thermocline. A 180 detailed description of the first order nonlocal KPP fundamentals is given in Large et al. 181 (1994). The ocean model is embedded with varying sea-ice concentration at the higher 182 latitudes. The sea ice variability is simulated by a simple thermodynamical model of melting 183 and freezing of sea ice by local forcings. However, regions with sea ice will not be discussed in this study. A flux correction is applied to the ocean temperature and salinity tendency in order to reduce the climate drift, which is described in the following sub-section.

\section{c. Flux corrections}

188 The ACCESS-KPP model computes the diffusivity profiles at each grid point and then estimates the temperature and salinity profiles. Since ocean dynamics (mainly advection) are absent in the model the temperature and salinity drifts away from the observed reference values for a longer run (many decades). So it is necessary to add flux corrections in order to prevent climate drift. The flux correction values are computed such that the mean seasonal cycle of temperature and salinity closely follow the climatology from WOA09 (Antonov et

194 al. 2010; Locarnini et al. 2010). The temperature and salinity flux corrections are obtained in 195 a number of iterations with the ACCESS-KPP model, where temperature and salinity are free 196 to evolve. In each iteration biases between the model variables and the climatological values are then computed and added as an additional forcing to the model's tendency equation in the next iteration. This process is repeated until the biases between the model variables and the climatological reference values are sufficiently small. The flux corrections vary at each grid point and for each month of year but are state independent and remain the same from one year to the next. Characteristics of the flux correction terms are discussed in the analysis section (see section 4.4). 
205 A wide range of criteria exists for defining MLD from the vertical profiles of temperature, salinity or density. Generally, these criteria fall into two categories: the difference criteria and

207 the gradient criteria. The difference criteria define the MLD as the depth where the oceanic 208 property has changed by a critical value from a reference depth near to the surface (Kara et 209 al. 2000; Montégut et al. 2004). The gradient criteria detect the shallowest depth where the 210 vertical gradient of the oceanic tracers exceeds a given value (Brainerd and Gregg 1995; 211 Lorbacher et al. 2006). The difference criterion largely depends on the difference value 212 chosen and produces misrepresentation of the MLD in regions of weakly stratified surface 213 layers. The gradient criteria also depend on the threshold value chosen for the derivative, but 214 since the gradient is expected to be large at the base of the MLD, it gives more accurate 215 estimations of MLD. Lorbacher et al. (2006) further developed the gradient criteria by adding 216 the standard deviation threshold to assume the shallowest extreme curvature. As a first guess, 217 the nearest MLD is assumed at the local maximum/minimum of the second derivative of the 218 gradient and where the gradient exceeds 0.25 of gradient maximum of the profile. As a secondary boundary condition, $30-\mathrm{m}$ standard deviation $(>0.02)$ is included to distinguish the near-homogeneous region and a standard deviation of gradient over the upper level is then set

$221\left(0.004 \mathrm{~km}^{-1}\right.$ for high and $0.002 \mathrm{~km}^{-1}$ for low resolution). A more accurate estimation of MLD 222 is provided by an exponential interpolation method (for thick layers), and hence the 223 Lorbacher et al. (2006) criteria is used to estimate the mixed layer from the density profiles 224 for all the data in this study. The results in this paper also hold when difference criteria are used for estimating MLD. We checked with difference in density of $0.03 \mathrm{~kg} / \mathrm{m}^{3}$ and variable density criteria (Montégut et al. 2004) that results shallower or deeper ML than that obtained by Lorbacher et al, (2006). However, the spatial pattern remain fairly similar for all the 228 criteria.

\section{Observed MLD}

231 As a starting point for the analysis the seasonal mean MLD estimated from GECCO2 are presented in Fig. 1 (left column). They are largely consistent with those found in previous studies (Kara et al. 2003; Montégut et al. 2004; Lorbacher et al. 2006). Fig. 2 simplifies the seasonal mean MLDs to the annual mean and the relative strength of the seasonal cycle. They show a number of well-known characteristics, such as the strong seasonal cycle in the extratropical regions or the shallow MLDs in the upwelling regions along coastlines and the equatorial Pacific. Overall the structure of the global ocean seasonal mean MLD is fairly 
complex. To simplify the following discussions and analyses it is useful to define some basic MLD regimes, based on the annual mean MLD and the relative strength of the seasonal cycle

240 (Fig. 2). The regime selection criteria where somewhat guided by a good presentation of the 241 following analysis. In terms of MLD the global ocean can be split into the following three 242 regimes:

- Extra-tropical-seasonal: Regions where the standard deviation of the seasonal cycle is larger than $60 \%$ of the annual mean MLD (Fig. 3a). The criteria $(60 \%)$ cover the regions where significant seasonal variability occurs. These are regions with a very shallow warm-season MLD and a substantially deeper cold-season MLD. This is mostly found in a band along 30-40 degrees with some regions extending further to higher latitudes. The most extreme seasonality is seen in the Southern Ocean in the Indian and Pacific sections, which are within the Antarctic Circumpolar Current (ACC) (Sallée et al. 2006; Dong et al. 2008). The far northern Atlantic is also a region of extreme seasonality.

- Constant-deep: Regions with an annual mean MLD > 30m and a standard deviation of the seasonal cycle that is less than $60 \%$ of the annual mean MLD (Fig. 3b). The $30 \mathrm{~m}$ selection criteria roughly mark half-standard-deviation away from the global mean MLD. These are mostly the off-equatorial tropical and subtropical regions, but also large fractions of the Southern Ocean and parts of the far northern Pacific.

- Constant-shallow: Regions with an annual mean MLD $<30 \mathrm{~m}$ and a standard deviation of the seasonal cycle that is less than $60 \%$ of the annual mean MLD (Fig. 3c). These mark mostly coastal regions and in particular upwelling regions along major continents and equatorial regions, but also coastlines in the north-western North Atlantic and west of Australia. Most of the North Indian Ocean falls in this shallow regime. But in NCEP-GODAS much of the North Indian Ocean falls in the constantdeep regime. It should be noted that MLD in NCEP-GODAS (annual mean is $\sim 52 \mathrm{~m}$ ) is deeper than the other two reanalyses data $(\sim 41 \mathrm{~m}$ in GECCO2 and SODA). The difference could be associated with different model assimilation procedures (Kröger

267 The following analysis focuses on how these different mean MLD regimes relate to the local 268 atmospheric forcing and the stratification of the upper ocean. 
271 The external forces that act on the MLD are the heat, momentum and evaporation272 precipitation difference (E-P) fluxes. All these forces interact with and influence the upper273 ocean stratification. Strongly stratified profiles require strong forcing to break the 274 stratification and to promote deepening of the mixed layer (ML). A comparison of the annual 275 mean values of the atmospheric forcings and the upper-ocean stratifications (Fig. 4) with the 276 annual mean MLD (Fig. 2a) gives some idea of the relative importance of the different 277 forcings. Note that the shading in Fig. 4 is coded in such a way that bluish colours indicate 278 forcings or stratifications that would support deeper mixed layers, and reddish colours 279 indicate forcings or stratifications that would support shallower MLD.

280 The annual mean net heat flux (NHF) in the higher latitudes $\left(>40^{\circ}\right)$ is mostly negative, which 281 implies that the ocean is losing heat (Fig 4a). Heat loss at the surface makes the upper ocean 282 statically unstable, which tends to deepen the ML. The upwelling regions along the coastlines 283 and the equator and in the tropical Indian Ocean are marked by annual mean heat gain, which 284 tends to support shallow MLD. Overall there is only a moderate match between the annual 285 mean NHF forcing and the MLD (spatial correlation of -0.3). Most of the constant-shallow MLD regime seems to be associated with annual mean heat gain. Also many of the extratropical regions with deeper annual mean MLD are associated with corresponding heat loss. However, many regions with shallower than global mean MLD are associated with annual mean heat loss, which does not support the observed shallow MLD (e.g. coastal regions in the western North Pacific and Atlantic and southern subtropical regions in the Indian and Pacific Oceans). Also regions with deeper than global mean MLD are associated with annual mean heat gain, which does not support the observed deep ML (e.g. off-equatorial tropical Pacific and parts of the Southern Ocean).

The annual mean wind-stress forcing (Fig. 4b) shows a slightly better match to the annual mean MLD than NHF (spatial correlation of 0.4). In particular, higher-latitude regions with deep annual mean ML are associated with strong mean wind-stress and equatorial regions with shallow annual mean MLD are associated with weak mean wind-stress. However, there are also large regions where the annual mean MLD is deep despite fairly moderate annual mean wind-stress (e.g. latitude bands around 30 degrees in both hemispheres) and regions where the annual mean MLD is shallow despite fairly strong annual mean wind-stress (e.g. subtropical South Indian Ocean and the Arabian Sea). One can also notice that for most regions NHF and wind-stress have similar influences on the MLD, with both either supporting deeper ML (e.g. most extra-tropical regions) or supporting shallower ML (e.g. 
equatorial regions). Notable exceptions here are parts of the subtropical regions, parts of the

305 Southern Ocean, the far northern Pacific, the western North Atlantic and the Arabian Sea.

306 The precipitation and evaporation (E-P) plays in general a minor role in mixing processes in

307 the upper ocean by changing the density structure (Dong et al. 2009), which is also

308 highlighted here by the mismatch of the annual mean E-P (Fig. 4d) with the annual mean

309 MLD for most regions (spatial correlation of 0.0). The mean E-P forcing is also mostly

310 unrelated to the NHF and wind-stress forcings. In some regions, however, where both NHF

311 and wind-stress forcings do not match the MLD, the E-P forcing does indeed seem to match

312 the MLD. These appear to be mostly smaller and coastal regions (e.g. coastal regions of

313 Greenland and some parts of the western boundary of the North Pacific and Atlantic).

314 Remarkable are the shallower MLD regions in the subtropical Indian and western Pacific

315 Oceans. Here, all three atmospheric forcings would support deeper annual mean MLD. The

316 shallower MLDs here seem to match the stronger upper-ocean stratifications, displayed in

317 Fig. 4c (spatial correlation of -0.5 ) in terms of the density gradient between the surface and

$318100 \mathrm{~m}$ depth. Although, upper-ocean stratification is partly a reflection of the atmospheric

319 forcings, it is also influenced by oceanic processes. Since the annual mean atmospheric

320 forcings seem to mismatch the mean MLD in these regions, it suggests that oceanic processes

321 independent of the local atmospheric forcing contribute to the stratification of the upper

322 ocean and thus a shallower MLD.

323

\section{$324 \quad 3.2$ The MLD seasonal cycle and its relationship with local forcing}

325 The extra-tropical-seasonal MLD regime largely represents the world ocean regions with strong mean MLD seasonal cycle (Fig. 2b). These regions are fairly well matched with the strength of the NHF seasonal cycle (Fig. 5a) with a spatial correlation of $\sim 0.6$. Although the wind-stress forcings in the Northern Hemisphere support the extra-tropical-seasonal MLD regime, they do not show strong seasonality in the Southern Hemisphere (Fig. 5b). Thus it seems that the extra-tropical-seasonal MLD regime is mostly a result of seasonally varying tendencies of heating and cooling at the surface. This is consistent with previous findings (Monterey and Levitus, 1997; Kara et al. 2003; Montégut et al. 2004). Also, seasonal variability in density gradients (Fig 5c) and E-P (Fig 5d) shows only a moderate match

334 (spatial correlation of 0.3 and -0.2 respectively) with the seasonality in MLD. However, again 335 there are some regions where this simple picture is not supported. In particular, the western 336 boundaries of the North Pacific and Atlantic have a very strong seasonal cycle in NHF, but 
not in the MLD. Also the very strong seasonality in the Indian and Pacific Oceans' ACC

338 regions are not directly matched by the seasonality in either of the atmospheric forcings.

339 An interesting aspect of the combined effect of annual mean forcing and the strength of the 340 seasonality in the forcings can be seen along the zonal bands in the northern midlatitudes

341 (Fig. 6). In the zonal band at around $30^{\circ} \mathrm{N}$ in the North Pacific the MLD is deeper on the 342 western side and it has a stronger seasonality. Both mean and seasonality decrease to the east.

343 This is supported by the behaviour of the mean heat flux and its seasonality. In the west an 344 annual mean cooling and strong seasonality support the MLD behaviour; to the east the mean cooling turns into a mean warming and the seasonality in NHF decreases, again supporting the MLD behaviour. This reflects the change in atmospheric forcing from having strong continental characteristics in the west (e.g. strong cooling in winter and strong seasonality) and being more in balance with the ocean state in the east, due to the preferred westerly wind conditions that tend to transport characteristics from the west to the east. This is somewhat similar in the North Atlantic, but the relationship breaks down near the western boundary region.

\subsection{Anomaly variability and its relationship with local forcing}

354 Next, it is interesting to regard the MLD variability beyond the seasonal cycle. The second column of Fig. 1 shows the standard deviation (stdv) of monthly mean MLD anomalies estimated for each season. The patterns of strong and weak MLD stdv match very well the patterns of deep and shallow mean MLD (first column in Fig. 1). Thus, MLD variability is stronger when the mean MLD is deep and MLD variability is weak when the mean MLD is shallow. This pattern even holds when we consider the coefficient of variance $(\mathrm{CV}$; the ratio of stdv over the mean) as shown in the last column of Fig. 1. The equatorial Pacific and Atlantic, however, mark regions where the MLD variability is strong even though the mean

362 MLD is fairly shallow, which is consistent with the study by Lorbacher et al. (2006). In these 363 regions the concept of MLD may not be so useful, as they are more dominated by lateral ocean wave dynamics in the thermocline. It is also remarkable to note that a CV $>100 \%$ is observed in the spring and winter seasons in the higher latitudes of North Atlantic and Pacific and in the Southern Ocean. This suggests a substantial amount of MLD variability. For most other regions the $\mathrm{CV}$ values are larger than 30\%, indicating significant MLD variability for most regions in most seasons. Keerthi et al. (2012) have also shown large CV values $(>40 \%)$ in the western and eastern equatorial Indian Ocean during boreal summer. 
370 Fig. 7 shows the cross-correlation between monthly mean MLD and NHF anomalies in-phase 371 and with one-month lead-time for the NHF for different seasons. Negative in-phase 372 correlations dominate in all seasons and most regions, consistent with cooling (negative NHF 373 anomalies) at the surface ocean leading to increased convective mixing and, hence, a deeper 374 ML; and vice versa for positive NHF anomalies. Equatorial regions in the central Pacific and 375 western Atlantic, however, show negligible correlation between NHF and MLD anomalies. 376 Further, the in-phase correlation in both hemispheres (in the midlatitudes) is stronger in fall 377 and winter and fairly weak in spring and summer. The one-month MLD lag cross-correlation 378 with NHF is largest in the fall season and weakest in the spring season in both hemispheres.

379 This relation is consistent with the idea that deeper MLDs evolve more slowly and therefore 380 have a longer lag-time relation between forcing (NHF) and MLD anomaly.

381 The wind-stress forcing is in most regions positively correlated with MLD, consistent with 382 stronger than normal wind-stress anomalies leading to deeper MLDs, and vice versa for 383 negative wind-stress anomalies (Fig. 8). In the mid to higher latitudes this relationship tends 384 to be stronger in spring and summer. The strongest correlations are essentially found in two 385 regions: the off-equatorial tropical and subtropical regions with a tendency for stronger correlations in the warmer season, and the extra-tropical higher latitudes in the Southern 387 Ocean and to a smaller extent in the far northern Pacific and Atlantic. The lag one-month 388 correlation overall appears to be strongest in the subtropical regions and in the fall season in 389 the Southern Ocean.

390 The cross-correlations of MLD with both NHF and wind-stress are mostly on a similar level, 391 with some more widespread and clearer correlation for the NHF with MLD. Cross392 correlations of MLD with E-P are in general weaker than those with NHF and wind-stress, 393 but are mostly positive, which is consistent with increased evaporation (salinity forcing) 394 leading to deeper MLs (see SFig. 1). This relationship is strongest in fall and winter seasons 395 in both hemispheres.

\section{4. The ACCESS-KPP model}

398 We now take a look at the MLD and its relation to the atmospheric forcings in the ACCESS399 KPP model with a single-column ocean mixed layer model. Thus, in this model the simulated 400 MLD is purely a result of local atmospheric forcing, vertical mixing and a heat and salinity 401 flux correction, which is independent of the background state, to prevent the model from 402 drifting away from the observed mean density profiles. 
403 A comparison of the patterns of the seasonal mean MLDs and its variability between observations (Fig. 1) and the ACCESS-KPP model (Fig. 9) already illustrates that the model represents the mean MLD characteristics very well. In the following, the same MLD

406 characteristics as above for observations will be analysed in the ACCESS-KPP model. 407 Further the role of the flux corrections in maintaining the realistic upper-ocean density 408 profiles will be investigated.

\subsection{The annual MLD and its relationship with local forcing}

411 The figures 10 and 11 show the same atmospheric forcings and upper-ocean stratification 412 fields as in figures 4 and 5, but for the ACCESS-KPP model. First of all one can notice that 413 the annual mean and seasonal cycle of the atmospheric forcings in the ACCESS-KPP model 414 are very similar to the observed values (spatial correlations are greater than 0.7 , see Table 1 415 in the supplementary material). This suggests that the MLD characteristics in the ACCESS416 KPP model can be analysed for similar atmospheric forcings conditions. Some mismatches 417 exist in the annual mean NHF in the northern Indian Ocean and tropical north Atlantic, where 418 the observed NHF is positive but the ACCESS-KPP model values are negative. However, 419 there are also some differences in these characteristics among the ocean reanalysis products 420 (see Table 2 in the supplementary material for spatial correlation between the ocean 421 reanalysis products), suggesting that such differences are not necessarily an indication of a 422 significant model bias.

423 The regional distribution of the annual mean MLD and the three main MLD regimes in the 424 ACCESS-KPP model are fairly similar to the observed (compare Figs. 12 and 13 with 2 and 425 3). The ACCESS-KPP model has a very similar regional distribution of the extra-tropical426 seasonal MLD regime, it also simulates the constant-deep MLD regime with a subtropical 427 and Southern Ocean region and it simulates parts of the constant-shallow MLD regime in the 428 coastal upwelling regions. However, some significant differences between the ACCESS-KPP 429 model and the observations can be noted: first, the overall mean MLD in the ACCESS-KPP 430 model is deeper than observed (63m and $41 \mathrm{~m}$, respectively). Here it should be noted that 431 annual mean in the other ocean reanalysis product NCEP-GODAS is $\sim 52 \mathrm{~m}$ and for SODA it 432 is $\sim 41 \mathrm{~m}$. It must however be kept in mind that MLD in the model is predominantly driven by 433 the atmospheric forcing; the strong inclination of ML dynamics on atmospheric forcing could 434 be a reason for relatively deeper ML in the model. The model also misses several regions 435 within the constant-shallow MLD regime: the equatorial cold tongues, the tropical Indian 436 Ocean and the northern oceans coastal regions. The model's extra-tropical-seasonal MLD 
437 regime is also slightly more widespread in the northern oceans than observed. Further, the 438 ACCESS-KPP model simulates fairly deep ML in the eastern subtropical Pacific and 439 subtropical Indian Ocean, which is much shallower in the observations. The deeper ML in

440 these regions seems to fit to fairly strong annual mean local atmospheric heat and wind 441 forcings. It thus seem to indicate that the observed shallow ML in these regions does not 442 result from the local forcing, but may involve interactive lateral ocean dynamics not 443 represented in the single-column ACCESS-KPP model. The northern North Atlantic shows 444 deeper MLs in the model despite weak wind forcing compared to the observed. In the model, 445 stronger cooling (compared to the observed) as well as statically less stable upper-ocean 446 (caused by relatively high surface salinity) results in overturning to great depth producing 447 deeper MLs in this region.

448 The relationship between the atmospheric forcings and the MLD in the ACCESS-KPP model 449 is also similar to the observed (compare Figs. 4 and 10). Again the wind-stress forcing tends 450 to be more strongly related to the annual mean MLD than the heat flux forcing and again the 451 E-P forcing has no relationship with the annual mean MLD.

452

$453 \quad 4.2$ The seasonal cycle of MLD and its relationship with local forcing

454 As stated above, the model is able to reproduce the observed seasonal changes reasonably 455 well (compare Figs $2 b$ and $12 b$ ): it essentially captures the zonal bands of the strong extra456 tropical-seasonal MLD regime in the midlatitudes. Seasonal amplitude is weaker in the 457 tropics, subtropics and also in parts of the Southern Ocean. As already indicated in the 458 previous section, the ACCESS-KPP model tends to overestimate the seasonality in the 459 eastern North Pacific and the western coastal region in the North Atlantic. The model is good 460 at representing the mean summer MLD, but overestimates MLD during fall and spring. This 461 however, cannot be due to stronger seasonality in the atmospheric forcings, as they appear to 462 be similar or weaker than observed. This suggests that the ACCESS-KPP model is missing 463 some ocean dynamics necessary to capture these features.

464 The seasonal cycle of the atmospheric forcings is well captured by the ACCESS-KPP model 465 and again the relationship between the heating and wind-stress forcings and the MLD are 466 mostly as observed (compare Figs 5 and 11). Thus, the seasonality in the NHF is the main 467 forcing for the seasonal cycle of the MLD in ACCESS-KPP model.

468

\section{$469 \quad 4.3$ Anomaly variability and its relationship with local forcing}


470 The overall strength and seasonal distribution of the anomaly variability of the MLD in the

471 ACCESS-KPP model is very similar to the observed (compare Figs. 1 and 9). The stdv of the

472 MLD is mostly strong where the mean ML is deep, but it follows the mean MLD even more

473 closely than observed. Thus, the coefficient of variance is more homogenous in the ACCESS-

474 KPP model.

475 The correlation between heat flux and wind-stress forcings and the MLD in the model have 476 similar signs as in observations in all seasons, but are overall much stronger (compare Figs. 7 477 and 8 with 14 and 15). This could be related to both errors in the reanalysis dataset and to the 478 simplified dynamics of the ACCESS-KPP model. The observations include atmospheric heat 479 fluxes, ocean observations and the model simulation of the reanalysis model. Errors in these 480 elements will lead to inconsistencies between the forcings and the MLD. Subsequently, one 481 has to assume that the correlation between forcings and the MLD is decreased in the 482 observations. On the other hand, the ACCESS-KPP model has simplified dynamics that only 483 include local forcings and vertical mixing, neglecting all other lateral ocean dynamics. 484 Subsequently, one has to assume that the correlation between local forcings and the MLD is 485 artificially enhanced.

486 As in the observations the effect of the anomalous wind stress forcings is stronger in the 487 warmer, shallower MLD seasons. The lag-1 correlation of the heat flux is also stronger in the 488 cold, deep ML seasons as in the observations. The E-P also shows higher correlations with 489 MLD (see SFig.1 and 2) than observed, but still much weaker than the correlations with heat 490 flux and wind stress, suggesting that the E-P forcing is not as important.

\subsection{Missing dynamics and the role of flux corrections}

493 Although the ACCESS-KPP model represents the seasonal mean MLD and its variability 494 fairly well by only simulating the local atmospheric forcing and the vertical single column 495 dynamics, it does also have substantial limitations. A key aspect of the ACCESS-KPP model 496 is that additional heat and salt flux correction terms exist on all levels in the ocean model. 497 These flux corrections are essential in many regions to maintain the overall stratification in 498 the density profile of the ocean, see Fig. 16(a,b). Without in particular the heat flux 499 corrections (salinity corrections not shown), the ocean stratification in the tropics and 500 subtropics would collapse eventually (over periods longer than 10 years) and the warm 501 surface waters would mix all the way to the bottom layer of the KPP model (1000m depth). 502 This is indicated by the significant surface warming and subsurface cooling effect of the heat 503 flux correction over wide spread regions in the tropics and subtropics. This effectively 
stabilizes the density profile and thus maintains the ocean stratification. The flux correction shown in Fig 16a (upper 50m) are of comparable magnitude to the atmospheric heat flux

506 forcing (in Fig 4a). Also, the seasonal variability of heat flux correction in the upper 50m

507 (Fig 16c) is large (no seasonal variability in the subsurface levels, Fig 16d). Since the flux

508 corrections mimic the mean effect of the missing ocean dynamics, it suggests that interactive

509 lateral ocean dynamics not simulated in the ACCESS-KPP model are also important for

510 simulating the main MLD characteristics.

511

\section{5. Summary and Discussion}

513 In this study, the spatial and temporal relationship between the local atmospheric forcing and

514 the mean, seasonal cycle and variability of the MLD are analysed using a recent ocean 515 reanalysis product (GECCO2) and a single-column ocean model (KPP) coupled to an 516 atmospheric GCM (ACCESS1.3) over the global ocean. The aim of this study was to 517 understand the driving mechanisms of the MLD in different regions and to what extent these 518 can be understood in terms of local air-sea interactions. The focus was on the MLD 519 characteristics of the annual mean, the relative seasonal cycle strength and the variability 520 anomalous from the seasonal cycle. To further simplify the fairly complex characteristics 521 three main regimes were introduced based on the characteristics of the annual mean and the 522 relative seasonal cycle strength of the MLD.

523 First of all, the findings about the annual mean and the relative seasonal cycle strength of the 524 MLD can be summarised as follows:

- The annual mean MLD over most open ocean regions (away from sea ice and shallow coastal regions) follows the wind and heat forcing. Regions with stronger mean wind forcing tend to have larger annual mean MLD and regions with annual mean net heating tend to have shallower annual mean MLD. The annual mean wind forcing strength appears to be most strongly related to the annual mean MLD and stronger than the net heat forcing. Both of these forcing, however, show spatial correlations less than $\sim 0.5$ with the global pattern of the annual mean MLD, indicating that the relationship is more complex. The large flux correction needed to prevent model drift signifies that ocean dynamics are also important for simulating MLD.

- Remarkable are a few regions, in which neither of the atmospheric forcings seem to match the annual mean or seasonal cycle characteristics of the MLD. The shallower MLD regions in the subtropical Indian and western Pacific Oceans do not seem to 
relate to any of the three atmospheric forcing. The western boundaries of the North Pacific and Atlantic have very strong seasonal cycle in NHF, but not in the MLD. Also, the very strong seasonality in the Indian and Pacific Oceans' ACC regions are not directly related to the seasonality in either of the atmospheric forcings. Since the atmospheric forcings seem to mismatch the MLD characteristics (in the reanalysis datasets) in these regions and the single-column ocean model is also not able to simulate these characteristics, it suggests that oceanic processes independent of the local atmospheric forcing contribute to the stratification of the upper ocean and thus the MLD in significant ways.

- The annual mean E-P forcing is for most regions not related to the annual mean MLD, suggesting it is not a dominating forcing. However, in some regions, where both annual mean NHF and wind-stress tendencies do not match the MLD, the E-P forcing does indeed seem to play a role for the annual mean MLD (e.g. coastal regions of Greenland and some parts of the western boundary of the North Pacific and Atlantic).

- The relative seasonal cycle strength of the MLD is also mostly related to the relative seasonal cycle strength of the net heating and wind stress, but here the relationship with the net heating is stronger than with the wind forcing. Thus, the relative seasonal cycle strength of the MLD mostly follows the strength of the seasonal cycle in the net heating.

Alternatively the processes that dominate the three different MLD regimes can be summarised:

- Extra-tropical-seasonal: This regime of the MLD in the midlatitudes is primarily a result of the strong seasonal cycle in the heating. The seasonal cycle in heating is indeed strongest in the midlatitudes and matches the strongest relative seasonal cycle strength of the MLD fairly well. In this regime, however, the atmospheric storm track positions also play a major role as well as oceanic fronts and strong boundary currents that are not simulated in the model.

- Constant-deep: The regime, where the ML is fairly deep ( $>30 \mathrm{~m})$ throughout the year with no strong seasonal cycle, is mostly found in the subtropics and some high latitudes. These are regions with no strong annual mean heating nor cooling, no strong seasonal cycle in heating and the winds tend to be slightly less than the global mean.

- Constant-shallow: Shallow MLDs without strong seasonal cycles are mostly found in coastal regions, equatorial regions and the tropical Indian Ocean. Some of these 
regions are fairly well related to the local forcings, such as coastal and some equatorial upwelling regions. However, much of this constant-shallow MLD regime is not well matched with the local forcings and is not well simulated in the ACCESSKPP simulation, suggesting that local forcings and processes are not sufficient to explain these MLD characteristics. In particular, in the higher latitudes coastal regions, the central ocean basin equatorial regions and in the Indian Ocean the constant-shallow MLD regimes are not matched to local forcings or processes.

The analysis of the anomalous variability of MLD and how it relates to the local forcing can be summarised by the following main points:

- The overall strength of the MLD variability is in general proportional to the mean MLD, with stronger variability associated with a deeper mean MLD (e.g. cold season). The MLD variability appears to be quite significant with values of $30 \%$ to more than $100 \%$ of the seasonal mean MLD values.

- Most of this is well captured by the ACCESS-KPP model, but in some regions this is not well simulated by the model, including the equatorial Pacific. In higher latitudes the model does not simulate as strong MLD variability relative to the seasonal mean MLD as observed.

- MLD variability is mostly negatively correlated with heat flux variability and positively with wind stress variability. In the mid to higher latitudes the relationship to heating tends to be stronger in the cold (deep ML) seasons and the relationship to wind forcing tends to be stronger in the shallower MLD (warm) seasons. In seasons with deeper mean MLD the relationship to the atmospheric forcings tends to become stronger when the atmospheric forcings lead by about one month, which seems to be consistent with a larger inertia of the MLD when it is deeper.

- The ACCESS-KPP model is consistent with these observed relationships between the local atmospheric forcings and the MLD, but the relationships are significantly stronger in the model simulations. This may to some part reflect the simplification of the model to only local vertical mixing processes and neglecting other ocean dynamics, which leads to an overestimate of the role of local forcings on the MLD variability. But it may also point to errors in the reanalysis datasets that lead to inconsistencies between atmospheric forcings and the ocean state that artificially degrade the relationship between local forcing and the MLD. 
603 While overall the local forcing perspective provides a fairly good representation of most of 604 the MLD characteristics in the global oceans, it does have some limitations as mentioned 605 above. This is in particular highlighted by the fact that the ACCESS-KPP model does require 606 significant flux correction in temperature (most importantly) and also in salinity. These are 607 important to maintain upper-ocean stratification close to observations. Without such terms in 608 the ACCESS-KPP model, the upper-ocean stratification in most subtropical regions would 609 collapse after about 10 years and the MLD would deepen to the base of the ACCESS-KPP 610 model $(1000 \mathrm{~m})$. Thus, with the flux correction terms, the coupled single-column model 611 allows to study the upper ocean-atmosphere interaction with higher near-surface vertical 612 resolution incorporated with a better vertical mixing. This coupled framework is 613 computationally less expensive and allows identification of the role of atmospheric forcings

614 for the upper-ocean processes.

615 The analysis has shown that the MLD characteristics arise from complex interactions 616 between the local forcings, ocean stratifications and potentially lateral ocean dynamics. Most 617 of the results discussed here result from comparisons of the overall statistics of MLD and 618 local forcings in observations and in the ACCESS-KPP simulation. To further untangle the 619 interactions and the relative contribution of different forcings and different oceanic processes 620 it would require sensitivity experiments with the ACCESS-KPP or similar model simulations, 621 in which forcings or elements of the forcings are turned 'off' or in which processes are 622 altered or turned 'off'. However, this is beyond this study and is left for future analyses.

623

\section{Acknowledgments}

625 The authors would like to thank Australian National Computational Infrastructure, in 626 Canberra, for providing computational platform for simulation of the ACCESS-KPP coupled 627 model. The ARC Climate System Science (CE110001028) supported this study. Nicholas 628 Klingaman was funded by the National Centre for Atmospheric Science-Climate, a 629 collaborative centre of the Natural Environment Research Council, under agreement $630 \mathrm{R} 8 / \mathrm{H} 12 / 83 / 001$. 


\section{Reference}

632

633 Adamec D, Elsberry RL (1984) The use of mean atmospheric forcing in an ocean mixed-

634 layer model. Journal of Physical Oceanography 14:1670-1676

635

636 Alexander M, Scott J, Deser C (2000) Processes that influence sea surface temperature and 637 ocean mixed layer depth variability in a coupled model. Journal of Geophysical Research 638 105:16823. doi: 10.1029/2000JC900074

639

640 Antonov JI, Seidov D, Boyer TP, Locarnini RA, Mishonov AV, Garcia HE, Baranova OK, 641 Zweng MM, Johnson DR (2010) World Ocean Atlas 2009, Volume 2: Salinity. S. Levitus, 642 Ed. NOAA Atlas NESDIS 69, U.S. Government Printing Office, Washington, D.C., 184 pp. 643

644 Bates N (2001) Interannual variability of oceanic CO2 and biogeochemical properties in the 645 Western North Atlantic subtropical gyre. Deep Sea Research Part II: Topical Studies in 646 Oceanography 48:15071528. doi: 10.1016/S0967-0645(00)00151-X 647

648 Behringer DW, Xue Y (2004) Evaluation of the global ocean data assimilation system at 649 NCEP: The Pacific Ocean. Eighth Symposium on Integrated Observing and Assimilation 650 Systems for Atmosphere, Oceans, and Land Surface. Washington State Convention and 651 Trade Center, Seattle, Washington, pp 11-15

652

653 Bi D, Dix M, Marsland SJ, et al (2013) The ACCESS coupled model: description, control 654 climate and evaluation. Australian Meteorological and Oceanographic Journal 63:41-64. 655

656 Brainerd KE, Gregg MC (1995) Surface mixed and mixing layer depths. Deep Sea Research 657 Part I: Oceanographic Research Papers 42:1521-1543. doi: 10.1016/0967-0637(95)00068-H 658

659 Carton J, Grodsky S, Liu H (2008) Variability of the Oceanic Mixed Layer, 1960-2004. 660 Journal of Climate 21:10291047. doi: 10.1175/2007JCLI1798.1 661

662 Carton J, Giese B (2008) A Reanalysis of Ocean Climate Using Simple Ocean Data 663 Assimilation (SODA). Mon Wea Rev 136:29993017. doi: 10.1175/2007MWR1978.1 
665 Chen D, Busalacchi A, Rothstein L (1994) The roles of vertical mixing, solar radiation, and 666 wind stress in a model simulation of the sea surface temperature seasonal cycle in the tropical 667 Pacific Ocean. Journal of Geophysical Research: Oceans 99:20345-20359. doi:

$66810.1029 / 94 J C 01621$

669

670 Cronin M, Kessler W (2002) Seasonal and interannual modulation of mixed layer variability 671 at $0^{\circ}, 110^{\circ} \mathrm{W}$. Deep Sea Research Part I: Oceanographic Research Papers 49:117. doi:

$67210.1016 / \mathrm{S} 0967-0637(01) 00043-7$

673

674 Dommenget D, Latif M (2002) Analysis of observed and simulated SST spectra in the 675 midlatitudes. Climate Dynamics 19:277-288. doi: 10.1007/s00382-002-0229-9

676

677 Dommenget D, Latif M (2008) Generation of hyper climate modes. Geophysical Research 678 Letters. doi: 10.1029/2007GL031087

679

680 Dong S, Gille S, Sprintall J (2007) An Assessment of the Southern Ocean Mixed Layer Heat 681 Budget. J Climate 20:4425-4442. doi: 10.1175/JCLI4259.1 682

683 Dong S, Sprintall J, Gille S, Talley L (2008) Southern Ocean mixed-layer depth from Argo 684 float profiles. Journal of Geophysical Research: Oceans. doi: 10.1029/2006JC004051 685

686 Dong S, Garzoli S, Baringer M (2009) An assessment of the seasonal mixed layer salinity 687 budget in the Southern Ocean. J Geophys Res. doi: 10.1029/2008JC005258 688

689 Fasham M (1995) Variations in the seasonal cycle of biological production in subarctic 690 oceans: A model sensitivity analysis. Deep Sea Research Part I: Oceanographic Research 691 Papers 42:1111-1149. doi: 10.1016/0967-0637(95)00054-A 692

693 Godfrey J, Lindstrom E (1989) The heat budget of the equatorial western Pacific surface 694 mixed layer. J Geophys Res 94:8007-8017. doi: 10.1029/JC094iC06p08007 695 
696 Halkides D, Lee T (2009) Mechanisms controlling seasonal-to-interannual mixed layer

697 temperature variability in the southeastern tropical Indian Ocean. J Geophys Res. doi:

$698 \quad 10.1029 / 2008 J C 004949$

699

700 Hirons L, Klingaman N, Woolnough S (2015) MetUM-GOML1: a near-globally coupled 701 atmosphere-ocean-mixed-layer model. Geosci Model Dev 8:363-379. doi: 10.5194/gmd-8$702 \quad 363-2015$

703

704 Kantha L, Clayson C (1994) An improved mixed layer model for geophysical applications.

705 Journal of Geophysical Research: Oceans 99:25235-25266. doi: 10.1029/94JC02257

706

707 Kantha, L, Clayson C (2000) Small scale processes in geophysical fluid flows. International 708 Geophysics Series, vol. 67. Academic Press, New York, pp 157-160.

709

710 Kara BA, Rochford P, Hurlburt H (2000) An optimal definition for ocean mixed layer depth.

711 J Geophys Res 105:16803-16821. doi: 10.1029/2000JC900072

712

713 Kara BA, Rochford P, Hurlburt H (2003) Mixed layer depth variability over the global ocean.

714 J Geophys Res 108:3079. doi: 10.1029/2000JC000736

715

716 Keerthi M, Lengaigne M, Vialard J, et al (2012) Interannual variability of the Tropical Indian

717 Ocean mixed layer depth. Climate Dynamics 40:743-759. doi: 10.1007/s00382-012-1295-2 718

719 Klingaman N, Woolnough S (2014) The role of air-sea coupling in the simulation of the

720 Madden-Julian oscillation in the Hadley Centre model. QJR Meteorol Soc 140:2272-2286.

721 doi: $10.1002 /$ qj.2295

722

723 Köhl A (2014) Evaluation of the GECCO2 ocean synthesis: transports of volume, heat and

724 freshwater in the Atlantic. Quarterly Journal of the Royal Meteorological Society. doi:

$725 \quad 10.1002 /$ qj.2347

726

727 Kröger J, Müller W, Storch J-S (2012) Impact of different ocean reanalyses on decadal

728 climate prediction. Clim Dyn 39:795-810. doi: 10.1007/s00382-012-1310-7 
730 Large WG, McWilliams JC, Doney SC (1994) Oceanic vertical mixing: A review and a

731 model with a nonlocal boundary layer parameterization. Reviews of Geophysics 32:363-403.

732 doi: 10.1029/94RG01872

733

734 Large WG, Crawford GB (1995) Observations and simulations of upper ocean response to

735 wind events during the Ocean Storms Experiment. Journal of Physical Oceanography

$736 \quad 25: 2831-2852$

737

738 Locarnini RA, Mishonov AV, Antonov JI, Boyer TP, Garcia HE, Baranova OK, Zweng MM, 739 Johnson DR (2010) World Ocean Atlas 2009, Volume 1: Temperature. S. Levitus, Ed.

740 NOAA Atlas NESDIS 68, U.S. Government Printing Office, Washington, D.C., 184 pp.

741

742 Lorbacher K, Dommenget D, Niiler P, Köhl A (2006) Ocean mixed layer depth: A subsurface 743 proxy of ocean-atmosphere variability. Journal of Geophysical Research: Oceans. doi:

$744 \quad 10.1029 / 2003 J C 002157$

745

746 Maykut G, McPhee M (1995) Solar heating of the Arctic mixed layer. J Geophys Res

747 100:24691-24703. doi: 10.1029/95JC02554

748

749 Montégut C, Madec G, Fischer A, et al (2004) Mixed layer depth over the global ocean: An

750 examination of profile data and a profile-based climatology. Journal of Geophysical

751 Research: Oceans. doi: 10.1029/2004JC002378

752

753 Montégut C, Mignot J, Lazar A, Cravatte S (2007) Control of salinity on the mixed layer

754 depth in the world ocean: 1. General description. Journal of Geophysical Research: Oceans.

755 doi: 10.1029/2006JC003953

756

757 Monterey G, Levitus S (1997) Seasonal Variability of Mixed Layer Depth for the World

758 Ocean, NOAA Atlas NESDIS 14:100 p, Natl. Oceanic and Atmos. Admin., Silver Spring, 759 Md

761 Narvekar J, Kumar S (2006) Seasonal variability of the mixed layer in the central Bay of 
762 Bengal and associated changes in nutrients and chlorophyll. Deep Sea Research Part I:

763 Oceanographic Research Papers 53:820-835. doi: 10.1016/j.dsr.2006.01.012

764

765 Peter A, Hénaff M, Penhoat Y, et al (2006) A model study of the seasonal mixed layer heat

766 budget in the equatorial Atlantic. J Geophys Res. doi: 10.1029/2005JC003157

767

768 Polovina J, Mitchum G, Evans G (1995) Decadal and basin-scale variation in mixed layer

769 depth and the impact on biological production in the Central and North Pacific, 1960-88.

770 Deep Sea Research Part I: Oceanographic Research Papers 42:1701-1716. doi:

$771 \quad 10.1016 / 0967-0637(95) 00075-\mathrm{H}$

772

773 Qui B, Chen S, Hacker P (2004) Synoptic-Scale Air-Sea Flux Forcing in the Western North

774 Pacific: Observations and Their Impact on SST and the Mixed Layer. Journal of Physical

775 Oceanography 34:2148-2159. doi: 10.1175/1520-0485(2004)034<2148:SAFFIT >2.0.CO;2

776

777 Sabine CL, Feely RA, Gruber N, et al (2004) The oceanic sink for anthropogenic CO2.

778 Science 305:367-71. doi: 10.1126/science. 1097403

779

780 Sallée JB, Wienders N, Speer K, Morrow R (2006) Formation of subantarctic mode water in

781 the southeastern Indian Ocean. Ocean Dynamics 56:525-542. doi: 10.1007/s10236-005-0054$782 \mathrm{x}$

783

784 Swenson M, Hansen D (1999) Tropical Pacific Ocean Mixed Layer Heat Budget: The Pacific

785 Cold Tongue. J Phys Oceanogr 29:69-81. doi: 10.1175/1520-

786 0485(1999)029<0069:TPOMLH>2.0.CO;2

787

788 Takahashi T, Feely R, Weiss R, et al (1997) Global air-sea flux of CO2: An estimate based

789 on measurements of sea-air pCO2 difference. Proceedings of the National Academy of

790 Sciences 94:8292-8299. doi: 10.1073/pnas.94.16.8292

791

792 


\section{Figure Captions}

794

795 Fig 1: Seasonal statistics of MLD estimated from GECCO2 density profiles averaged over 796 January-March (a,b,c), April-June (d,e,f), July-September (g,h,i) and October-December 797 (j,k,l) for the period 1948-2011. The left column shows the seasonal mean MLD (a,d,g,j). The 798 standard deviations of the MLD calculated for each calender month and then seasonally 799 averaged are shown in the middle column (b,e,h,k). The right column $(\mathrm{c}, \mathrm{f}, \mathrm{i}, \mathrm{l})$ shows the 800 seasonal average of the monthly standard deviation relative to the corresponding monthly 801 mean MLD (i.e., the coefficient of variance).

802

803 Fig 2: (a) Annual mean MLD estimated from GECCO2 density profiles (30m contour 804 represents shallow mixed layer), and (b) Seasonal amplitude (computed as the standard 805 deviation of the monthly climatology) of MLD relative to the annual mean MLD and the 806 contour represents $60 \%$ variability.

807

808 Fig 3: Different MLD regimes based on GECCO2 dataset: (a) Extra-tropical-seasonal;

809 regions where seasonal amplitude change is $>60 \%$ of the annual mean MLD. (b) Constant-

810 deep; regions where MLD $>30 \mathrm{~m}$ and seasonal change is $<60 \%$. (c) Constant-shallow; regions 811 with $<60 \%$ relative seasonal change and MLD $<30 \mathrm{~m}$.

813 Fig 4: GECCO2 annual mean fields: (a) Net heat flux (NHF); positive/negative sign indicates 814 the ocean is gaining/losing heat, (b) wind-stress, (c) density gradient $\left(\mathrm{kg} / \mathrm{m}^{4}\right)$ between the 815 surface and 100m depth, and (d) evaporation minus Precipitation (E-P). Colour code is in 816 such a way that blue shading represents favourable for deep MLD and red shading for 817 shallow mixed layers. Spatial correlation (r) between the forcing variable and the annual 818 mean MLD (Fig 2a) is shown at the top left corner of the corresponding subplot.

820 Fig 5: Seasonal amplitude of GECCO2 variables (computed as the standard deviation of the 821 monthly climatology): (a) Net heat flux (NHF), (b) wind-stress, (c) density gradient $\left(\mathrm{kg} / \mathrm{m}^{4}\right)$ 822 between the surface and $100 \mathrm{~m}$ depth, and (d) evaporation minus Precipitation (E-P). Spatial 823 correlation ( $r$ ) between the seasonal change of the forcing variable and the MLD (relative to 824 the annual mean as in Fig 2b) is shown at the top left corner of the corresponding subplot. 
826 Fig 6: The annual mean MLD, net heat flux (NHF) and wind-stress (from GECCO2)

827 averaged along (a) $30^{\circ}-32^{\circ} \mathrm{N}$ (North Pacific) and (b) $33^{\circ}-35^{\circ} \mathrm{N}$ (North Atlantic). The

828 positive/negative heat flux (NHF) values indicate that the ocean is losing/gaining heat. The

829 coloured shading represents the corresponding seasonal amplitude change at each grid point

830 (light red for NHF, light blue for MLD and light yellow is for wind-stress).

831

832 Fig 7: Cross correlation of net heat flux (NHF) and MLD anomalies in different seasons from

833 GECCO2. Left column shows concurrent correlations and the right column represents the

834 corresponding one-month lag correlations, where MLD lags the forcing by one month. The

835 rows represent from top to bottom the different seasons: January-March (JFM), April-June

836 (AMJ), July- September (JAS), and October-November (OND). Significant (95\%) non-zero

837 correlation value is \pm 0.1 .

838

839 Fig 8: Cross correlation of wind stress (TAU) and MLD anomalies in different seasons from

840 GECCO2. Left column shows concurrent correlations and the right column represents the

841 corresponding one-month lag correlations, where MLD lags the forcing by one month. The

842 rows represent from top to bottom the different seasons: January-March (JFM), April-June

843 (AMJ), July- September (JAS), and October-November (OND). Significant (95\%) non-zero

844 correlation value is \pm 0.1 .

845

846 Fig 9: Seasonal statistics of MLD as in Fig 1 but for the ACCESS-KPP coupled model.

847

848 Fig 10: ACCESS-KPP annual mean fields (same as in Fig 4). Spatial correlation (r) between

849 the forcing variable and the annual mean MLD (in Fig 12a) is shown at the top left corner of

850 the corresponding subplot.

851

852 Fig 11: Seasonal amplitude of ACCESS-KPP forcing variables (same as in Fig 5). Spatial

853 correlation (r) between the seasonal change of the forcing variable and the MLD (relative to

854 the annual mean as in Fig 12b) is shown at the top left corner of the corresponding figure. 855

856 Fig 12: (a) Annual mean MLD estimated from ACCESS-KPP simulated density profiles

857 (30m contour represents the shallow mixed layer), and (b) Seasonal amplitude of MLD

858 relative to the annual mean MLD, with contour of $60 \%$ variability (similar to Fig 2). 
860 Fig 13: Different MLD regimes based on ACCESS-KPP simulation (same as in Fig 3)

861

862 Fig 14: Cross correlation of net heat flux (NHF) and MLD anomalies in different seasons as

863 in Fig 7 but for the ACCESS-KPP model. Significant (95\%) non-zero correlation value is

$864 \pm 0.1$.

865

866 Fig 15: Cross correlation of wind-stress (TAU) and MLD anomalies in different seasons as in 867 Fig 8 but for the ACCESS-KPP model. Significant (95\%) non-zero correlation value is \pm 0.1 .

868

869 Fig 16: Annual mean (a, b) and seasonal cycle (c, d) of heat flux correction applied on the 870 model levels (top) surface to 50m, and (bottom) 200-300m depth. The actual flux correction

871 at each model level is in $\mathrm{W} / \mathrm{m}^{3}$ and here we multiplied with the thickness of all the layers

872 (50m and $100 \mathrm{~m}$, respectively) to show the values in units of $\mathrm{W} / \mathrm{m}^{2}$. Seasonal cycle

873 corresponds to the standard deviation of monthly flux correction in $\mathrm{W} / \mathrm{m}^{2}$. The deeper levels

874 have no seasonal cycle corrections.

875

876 Supplementary Figure Captions

877

878 SFig 1: Cross correlation of E-P and MLD anomalies in different seasons from GECCO2.

879 Left column shows concurrent correlations and the right column represents the corresponding 880 one-month lag correlations, where MLD lags the forcing by one month. The rows represent 881 from top to bottom the different seasons: January-March (JFM), April-June (AMJ), July882 September (JAS), and October-November (OND). Significant (95\%) non-zero correlation 883 value is \pm 0.1 .

884 885

886 SFig 2: Cross correlation of E-P and MLD anomalies as in SFig 1 but for the ACCESS-KPP 887 coupled model. Significant (95\%) non-zero correlation value is \pm 0.1 .

890 Supplementary Tables

892 Table 1: Spatial correlation of variables in model and reanalyses data. The hyphen represents 893 missing or no data. 
895 Table 2: Spatial correlation of variables in GECCO2 and other reanalyses. (The values in 896 brackets are the spatial correlation of GODAS and SODA data). The hyphen represents 897 missing or no data.

898 


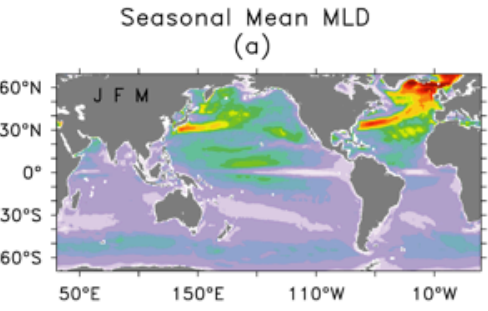

(d)

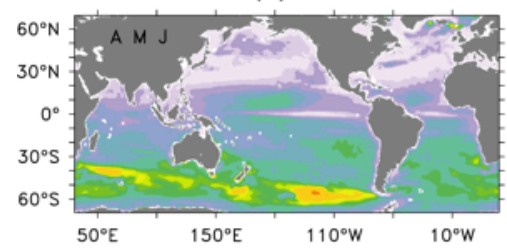

(g)

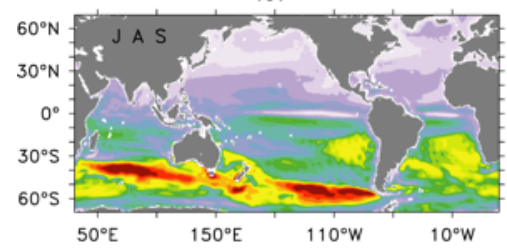

(J)

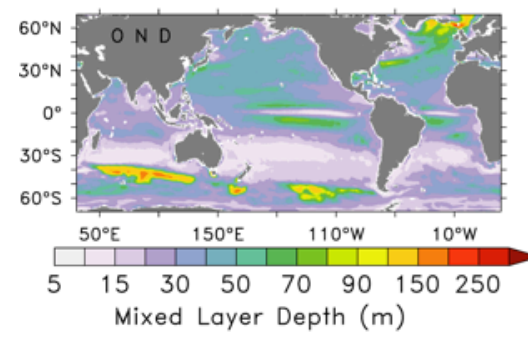

Standard deviation (STD)

(b)

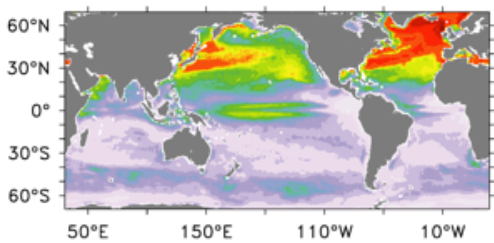

(e)

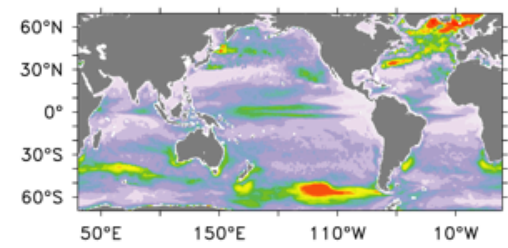

(h)

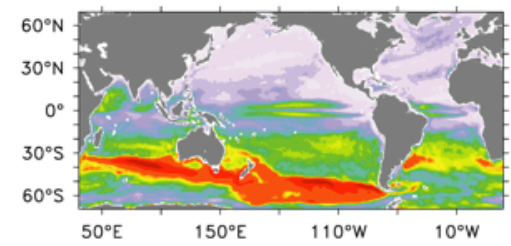

(k)

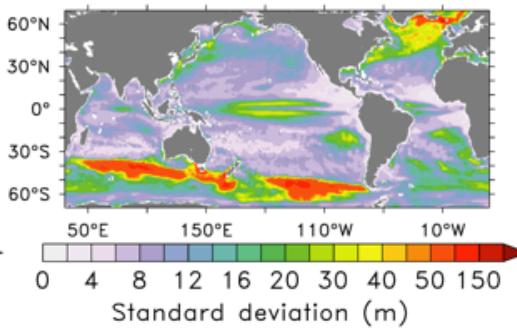

STD relative to Mean (CV)

(c)

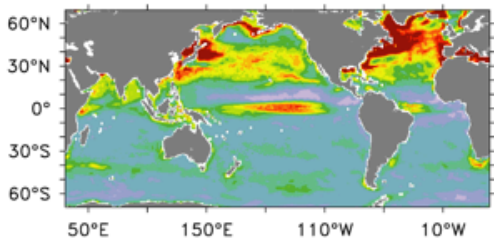

(f)

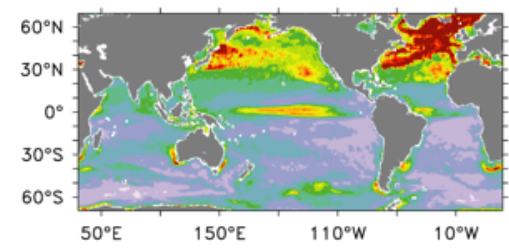

(i)

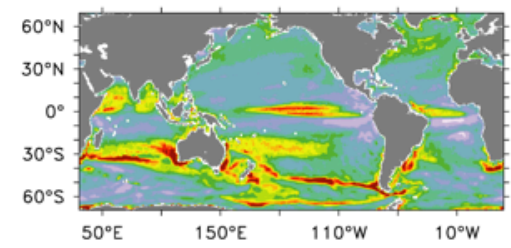

(I)

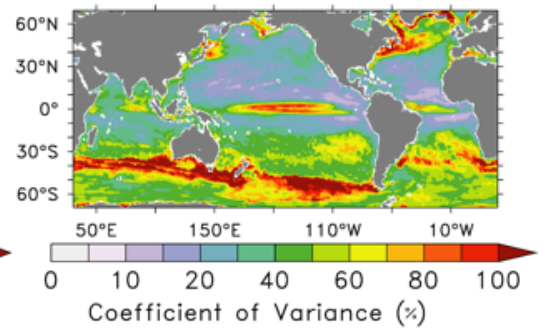

Fig 1: Seasonal statistics of MLD estimated from GECCO2 density profiles averaged over January-March (a,b,c), April-June (d,e,f), July-September (g,h,i) and October-December $(\mathrm{j}, \mathrm{k}, \mathrm{l})$ for the period 1948-2011. The left column shows the seasonal mean MLD (a,d,g,j). The standard deviations of the MLD calculated for each calender month and then seasonally averaged are shown in the middle column (b,e,h,k). The right column (c,f,i,l) shows the seasonal average of the monthly standard deviation relative to the corresponding monthly mean MLD (i.e., the coefficient of variance). 
(a) Annual Mean MLD

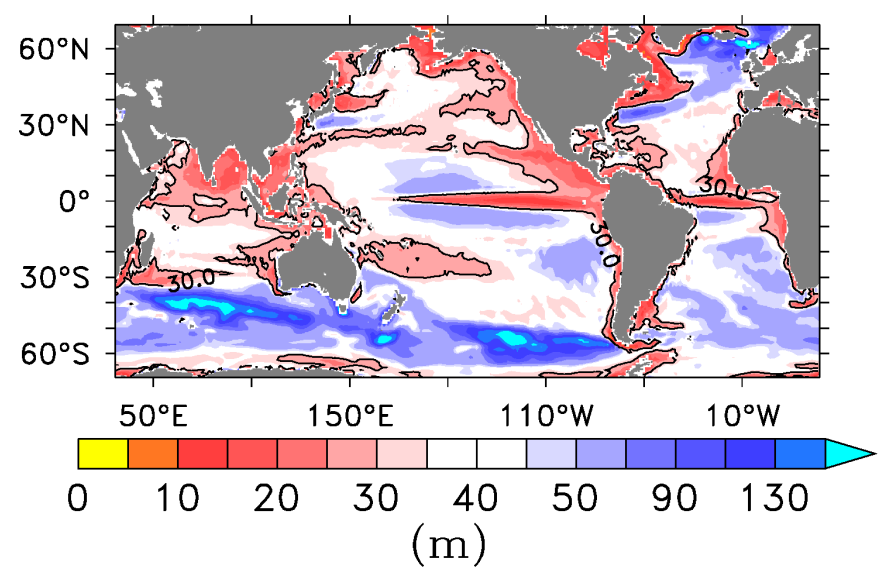

(b) Seasonal amplitude / Mean MLD

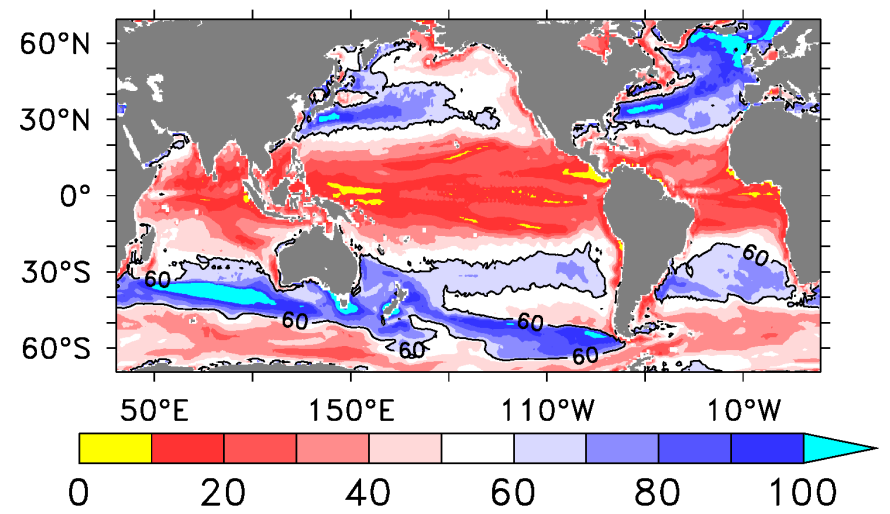

$(\%)$

Fig 2: (a) Annual mean MLD estimated from GECCO2 density profiles (30m contour represents shallow mixed layer), and (b) Seasonal amplitude (computed as the standard deviation of the monthly climatology) of MLD relative to the annual mean MLD and the contour represents $60 \%$ variability. 
(a) Extra-tropical-seasonal

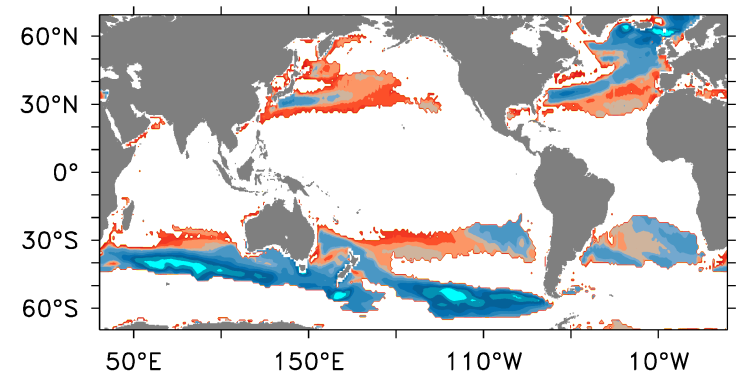

(b) Constant-deep

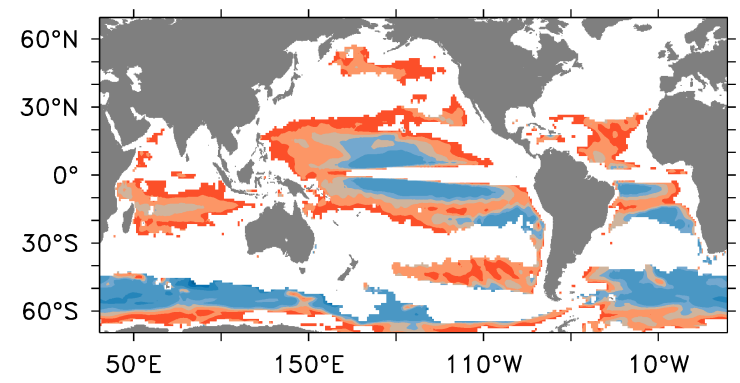

(c) Constant-shallow

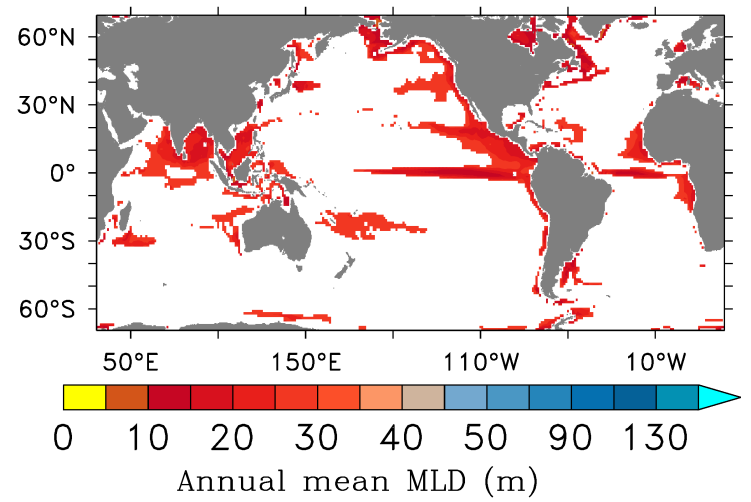

Fig 3: Different MLD regimes based on GECCO2 dataset: (a) Extra-tropical-seasonal; regions where seasonal amplitude change is $>60 \%$ of the annual mean MLD. (b) Constant-deep; regions where MLD $>30 \mathrm{~m}$ and seasonal change is $<60 \%$. (c) Constantshallow; regions with $<60 \%$ relative seasonal change and MLD $<30 \mathrm{~m}$. 
(a) Annual Mean NHF

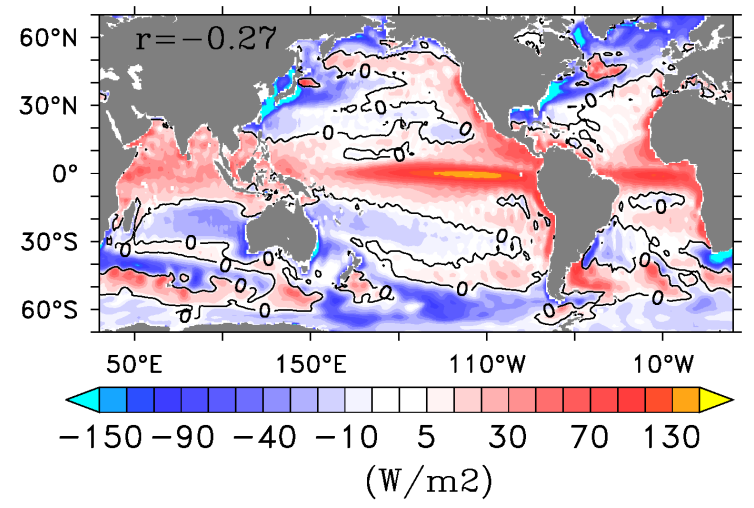

(c)Annual Mean Density gradient

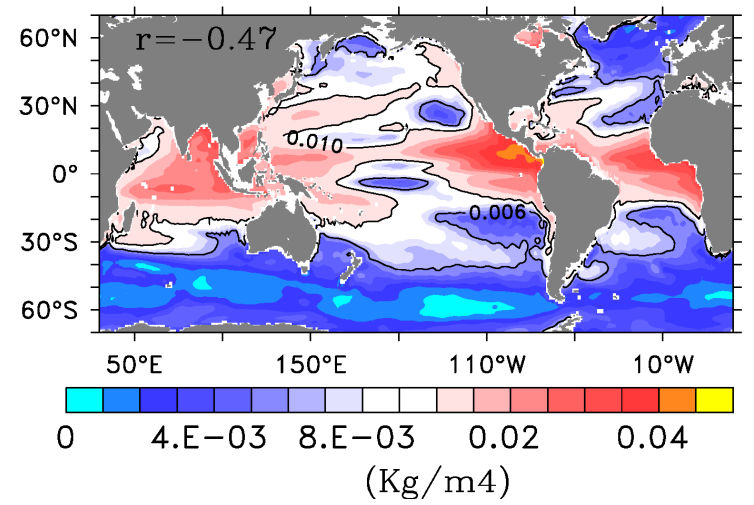

(b) Annual Mean Wind-stress

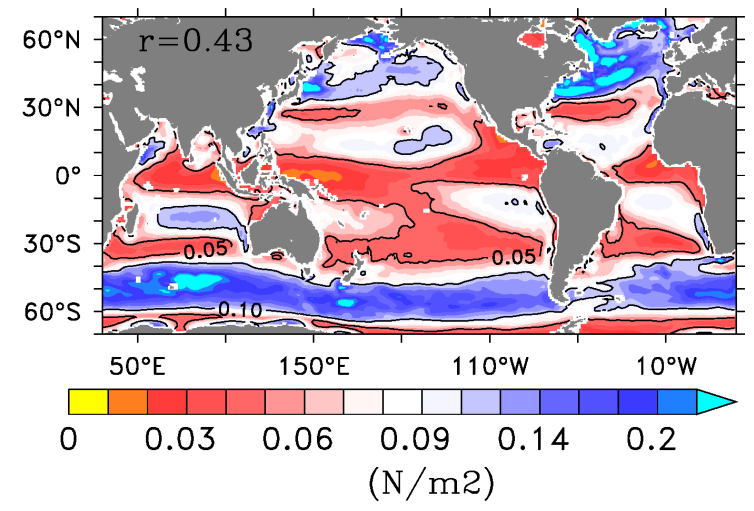

(d) Annual Mean E-P

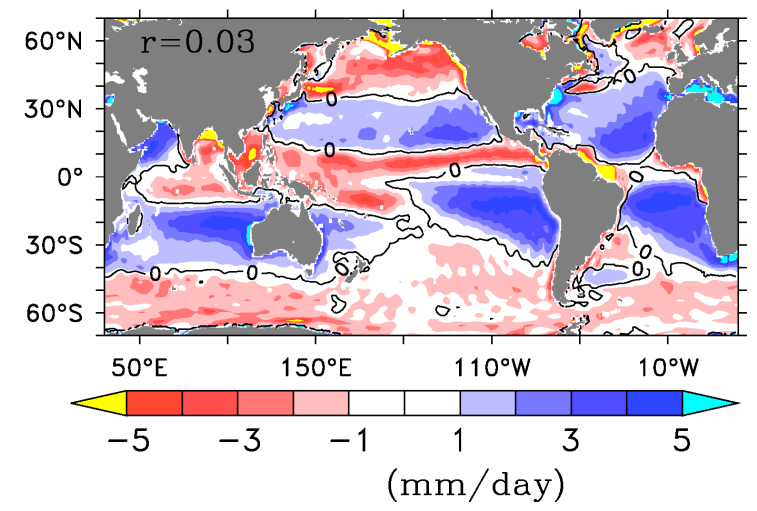

Fig 4: GECCO2 annual mean fields: (a) Net heat flux (NHF); positive/negative sign indicates the ocean is gaining/losing heat, (b) wind-stress, (c) density gradient $\left(\mathrm{kg} / \mathrm{m}^{4}\right)$ between the surface and 100m depth, and (d) evaporation minus Precipitation (E-P). Colour code is in such a way that blue shading represents favourable for deep MLD and red shading for shallow mixed layers. Spatial correlation (r) between the forcing variable and the annual mean MLD (Fig 2a) is shown at the top left corner of the corresponding subplot. 
(a) NHF Seasonal cycle

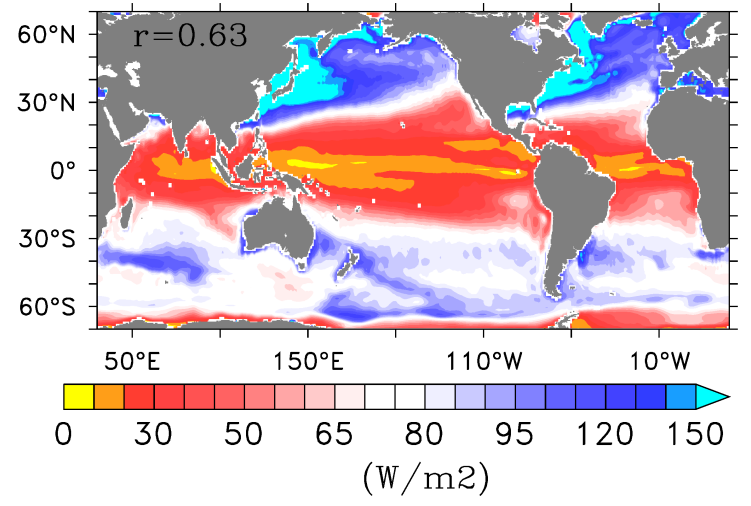

(c) Seasonal cycle of Density gradient

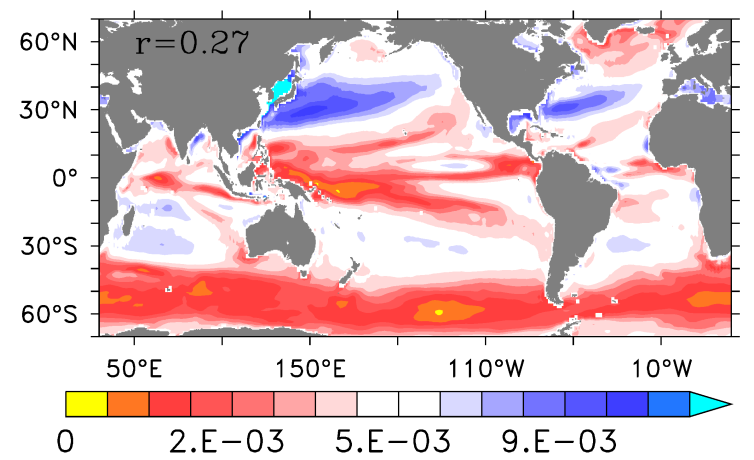

(b) Seasonal cycle of Wind-stress

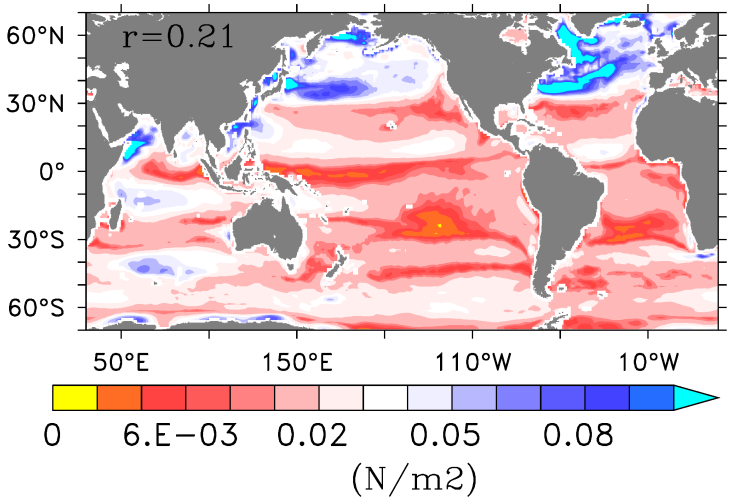

(d) Seasonal cycle of $\mathrm{E}-\mathrm{P}$

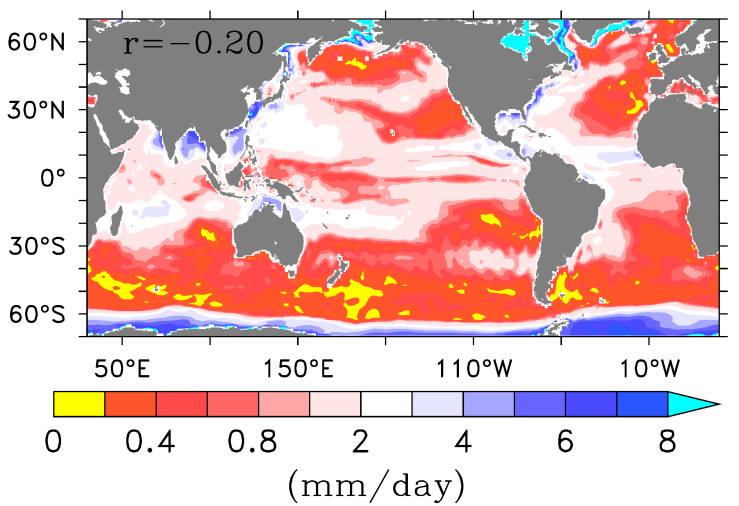

Fig 5: Seasonal amplitude of GECCO2 variables (computed as the standard deviation of the monthly climatology): (a) Net heat flux (NHF), (b) wind-stress, (c) density gradient $\left(\mathrm{kg} / \mathrm{m}^{4}\right.$ ) between the surface and 100m depth, and (d) evaporation minus Precipitation (E-P). Spatial correlation ( $r$ ) between the seasonal change of the forcing variable and the MLD (relative to the annual mean as in Fig 2b) is shown at the top left corner of the corresponding subplot. 
(a) North Pacific

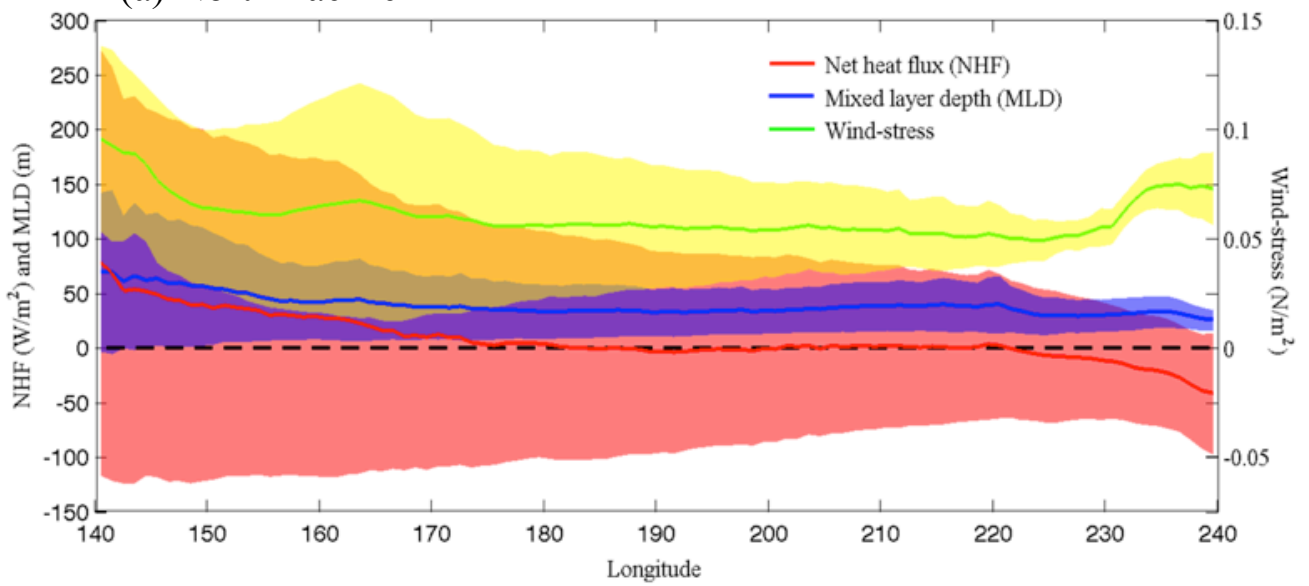

(b) North Atlantic

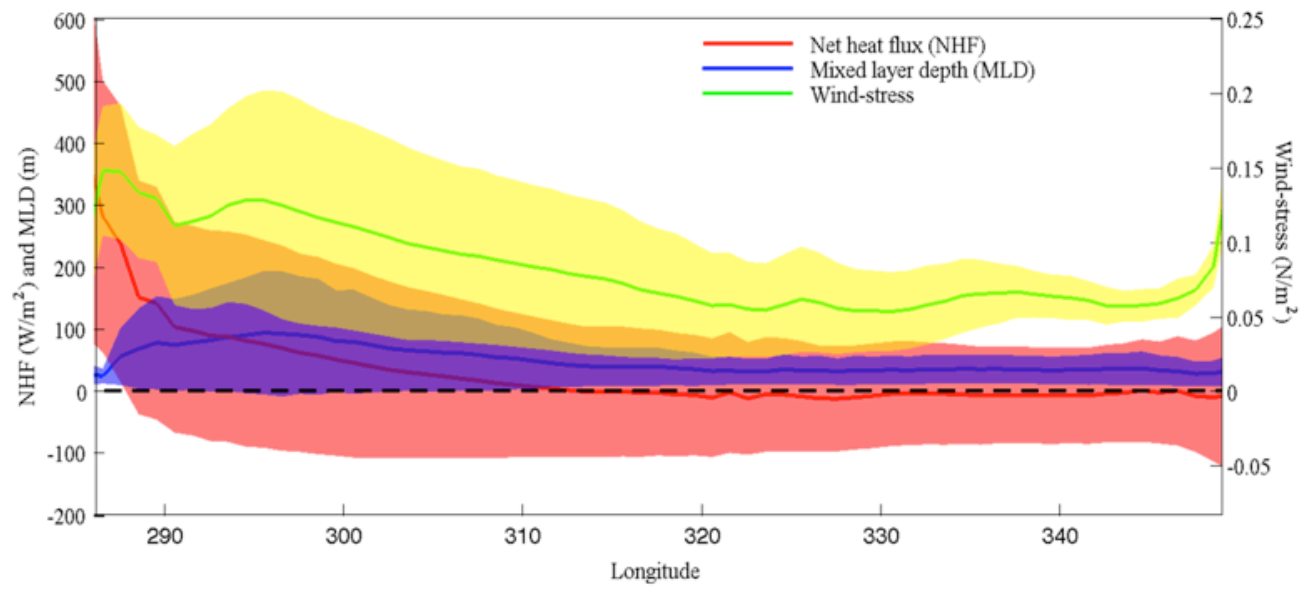

Fig 6: The annual mean MLD, net heat flux (NHF) and wind-stress (from GECCO2) averaged along (a) $30^{\circ}-32^{\circ} \mathrm{N}$ (North Pacific) and (b) $33^{\circ}-35^{\circ} \mathrm{N}$ (North Atlantic). The positive/negative heat flux (NHF) values indicate that the ocean is losing/gaining heat. The coloured shading represents the corresponding seasonal amplitude change at each grid point (light red for NHF, light blue for MLD and light yellow is for wind-stress). 
In-Phase Correlation

(a)

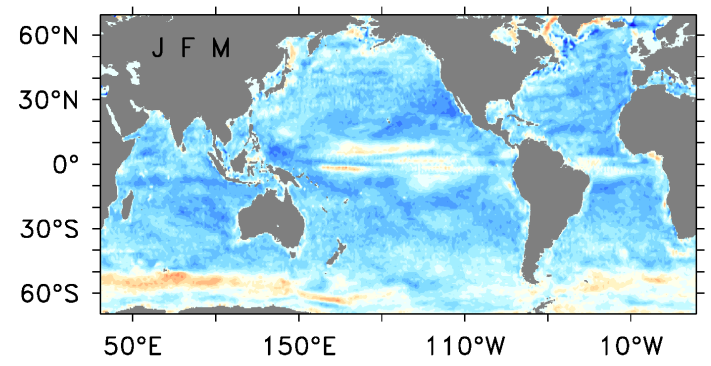

(c)

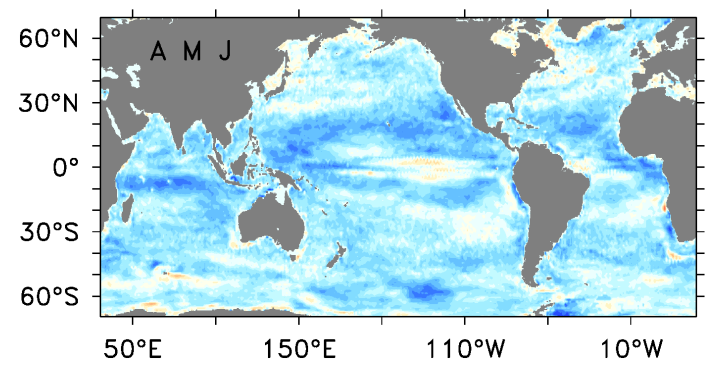

(e)

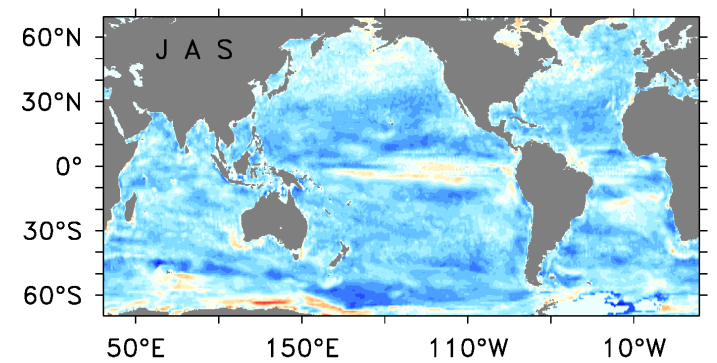

(g)

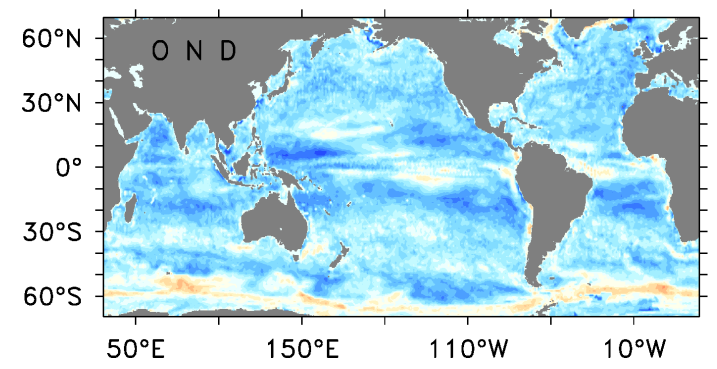

MLD Lag 1 month

(b)

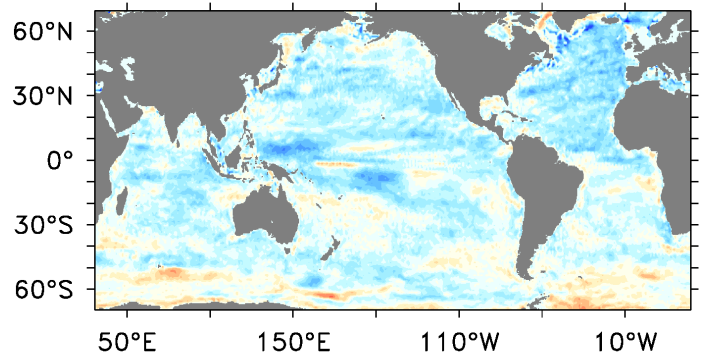

(d)

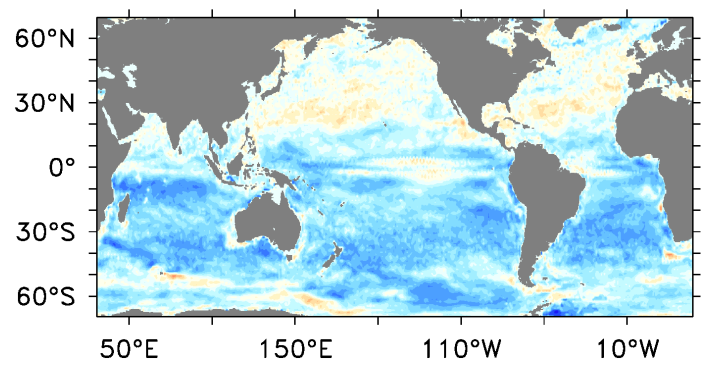

(f)

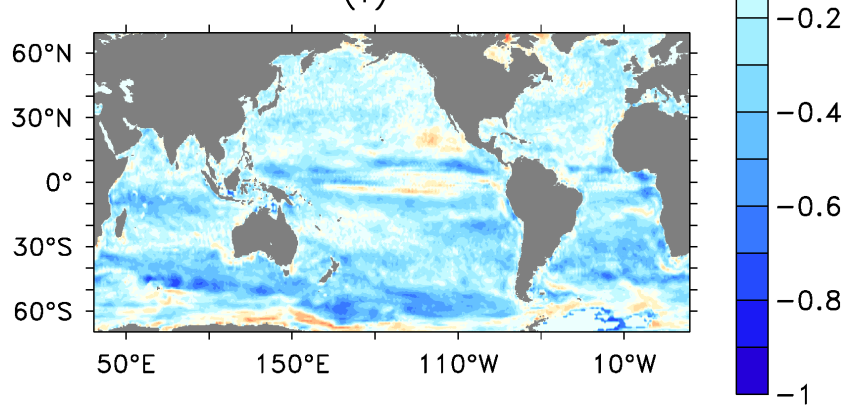

(h)

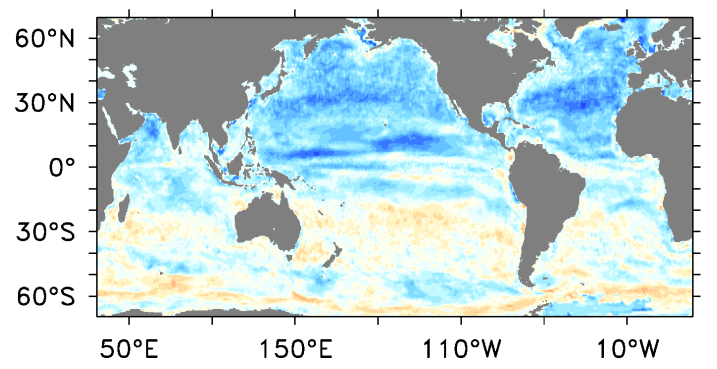

Fig 7: Cross correlation of net heat flux (NHF) and MLD anomalies in different seasons from GECCO2. Left column shows concurrent correlations and the right column represents the corresponding one-month lag correlations, where MLD lags the forcing by one month. The rows represent from top to bottom the different seasons: JanuaryMarch (JFM), April-June (AMJ), July- September (JAS), and October-November (OND). Significant (95\%) non-zero correlation value is \pm 0.1 . 
In-Phase Correlation

(a)

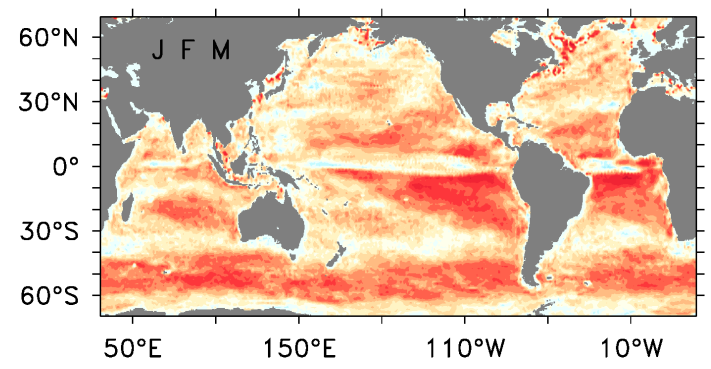

(c)

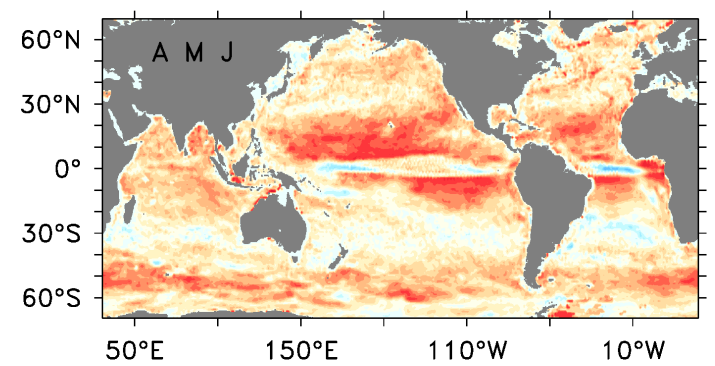

(e)

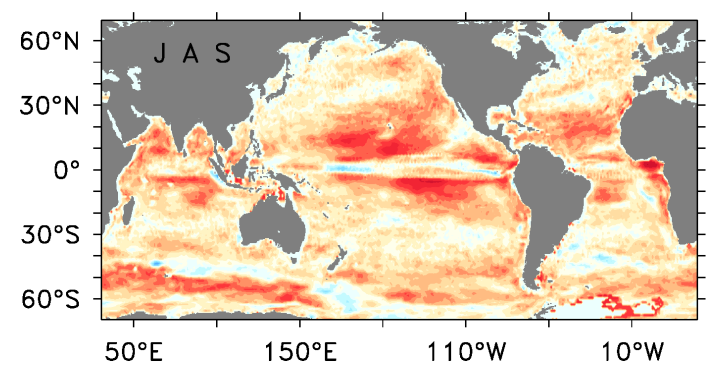

(g)

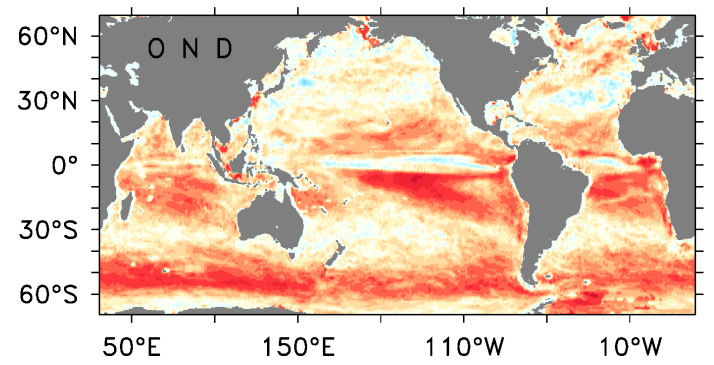

MLD Lag 1 month

(b)

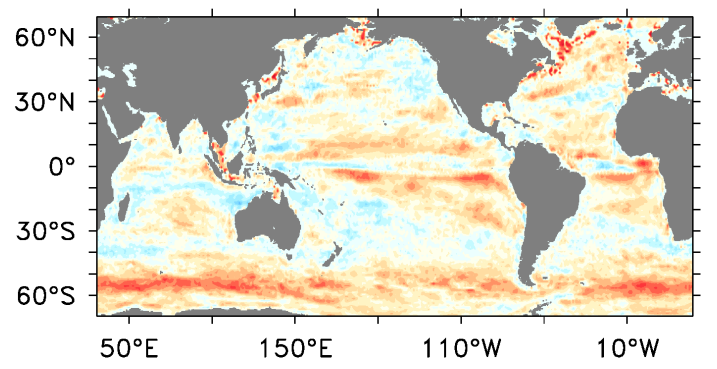

(d)

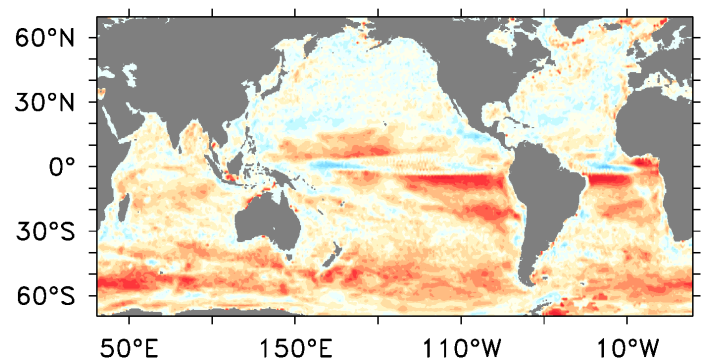

(f)

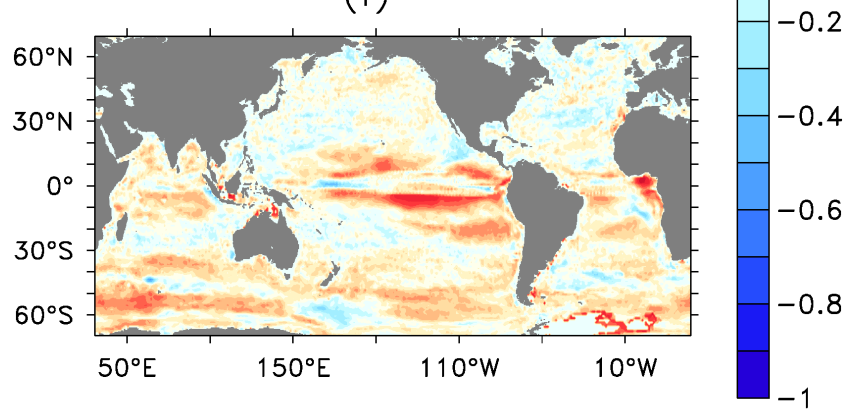

(h)

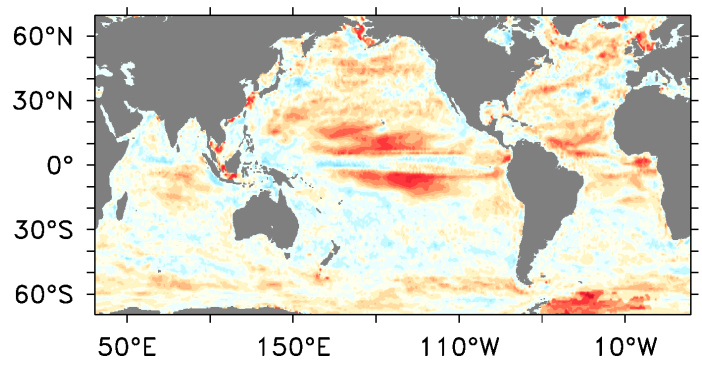

Fig 8: Cross correlation of wind stress (TAU) and MLD anomalies in different seasons from GECCO2. Left column shows concurrent correlations and the right column represents the corresponding one-month lag correlations, where MLD lags the forcing by one month. The rows represent from top to bottom the different seasons: January-March (JFM), AprilJune (AMJ), July- September (JAS), and October-November (OND). Significant (95\%) non-zero correlation value is \pm 0.1 . 
Seasonal Mean MLD

(a)

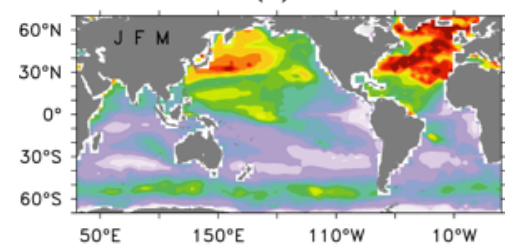

(d)

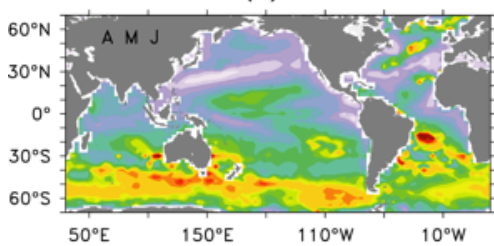

(g)

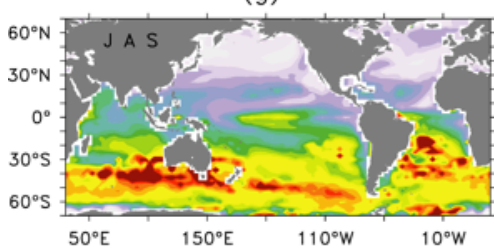

(J)

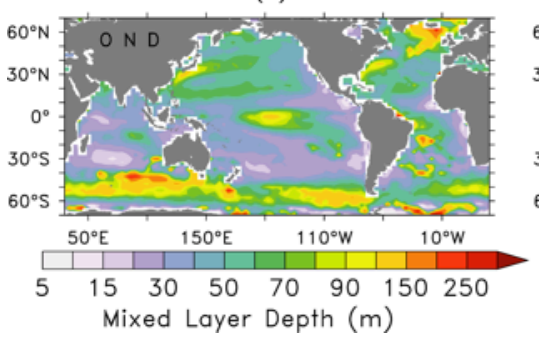

Standard deviation (STD)

(b)

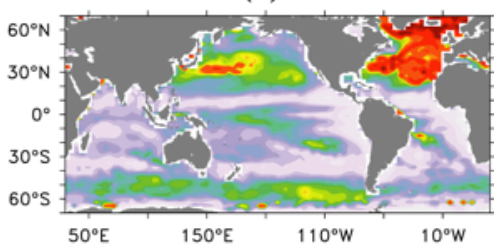

(e)

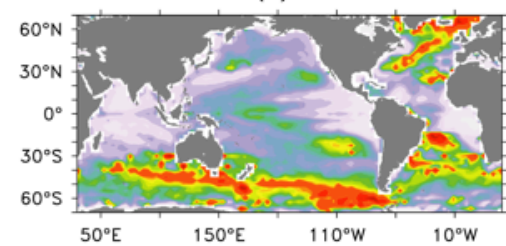

(h)

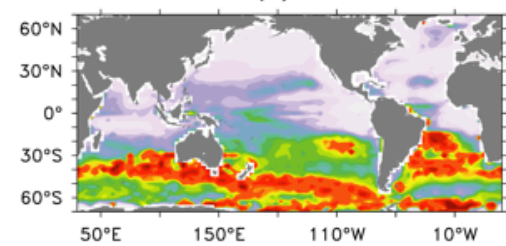

(k)

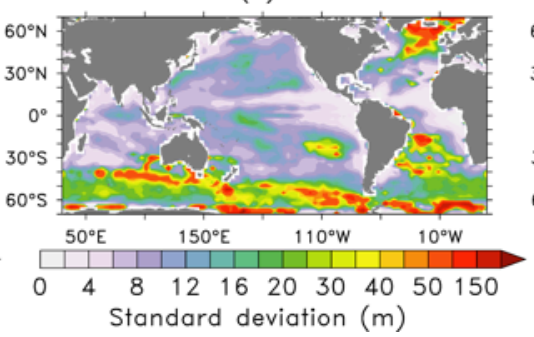

STD relative to Mean (CV)

(c)

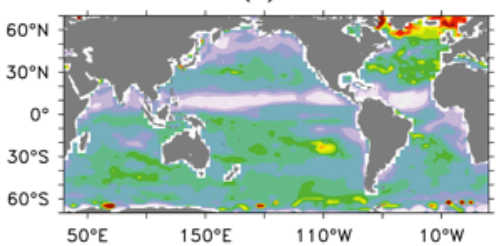

(f)

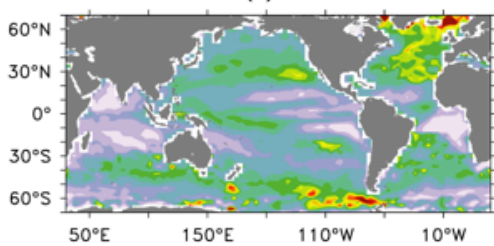

(i)

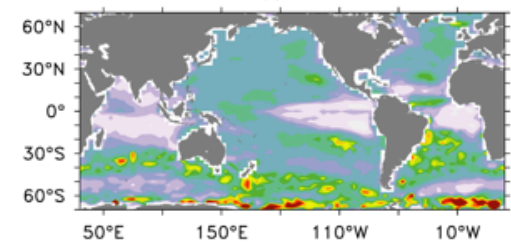

(1)

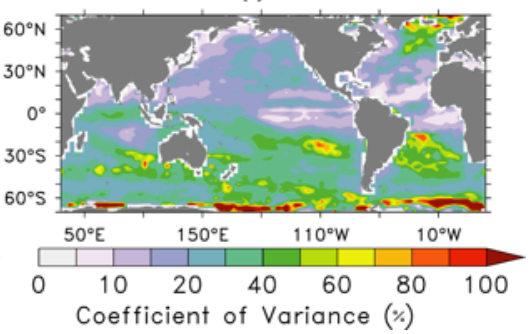

Fig 9: Seasonal statistics of MLD as in Fig 1 but for the ACCESS-KPP coupled model. 
(a) Annual Mean NHF

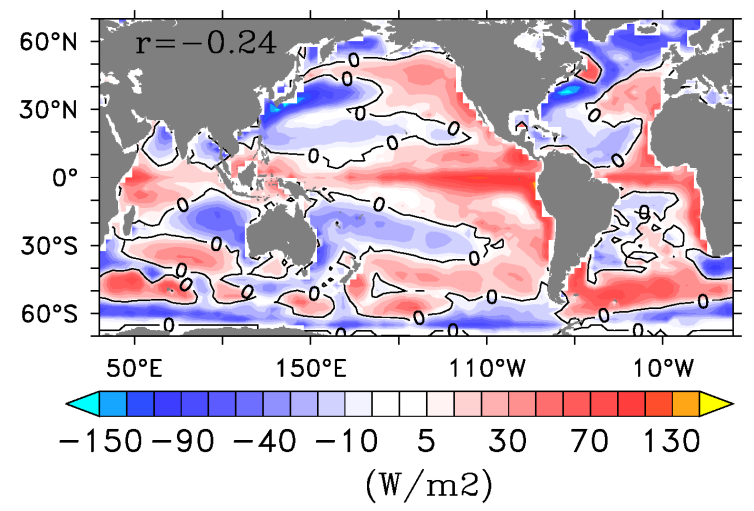

(c)Annual Mean Density gradient

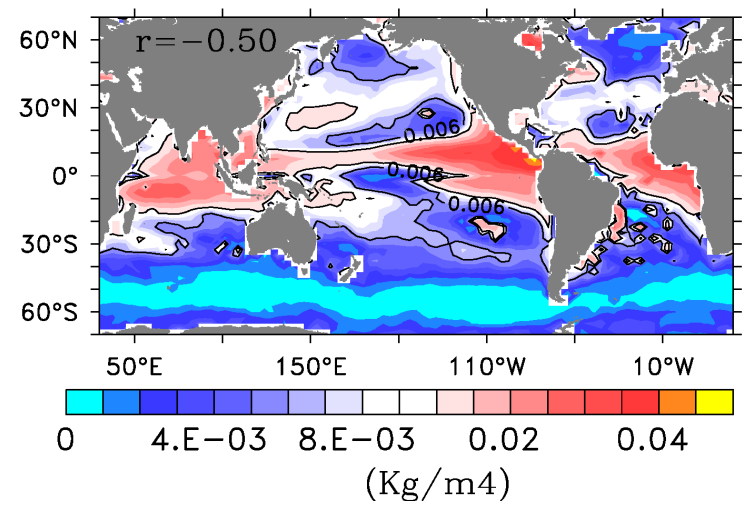

(b) Annual Mean Wind-stress

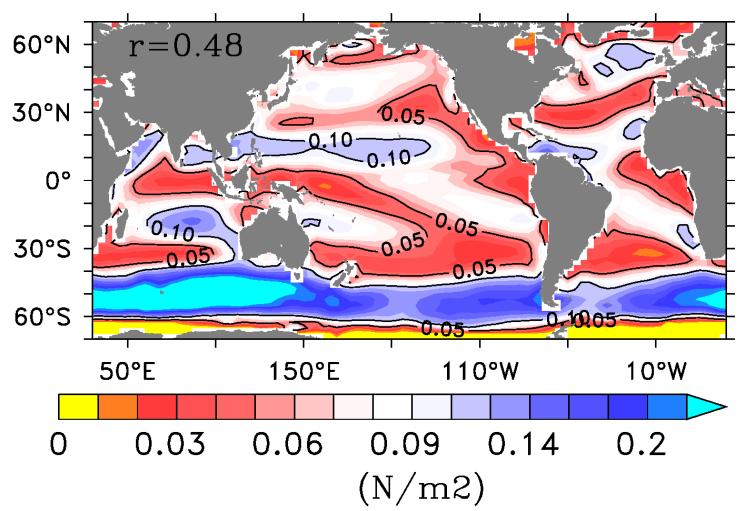

(d) Annual Mean E-P

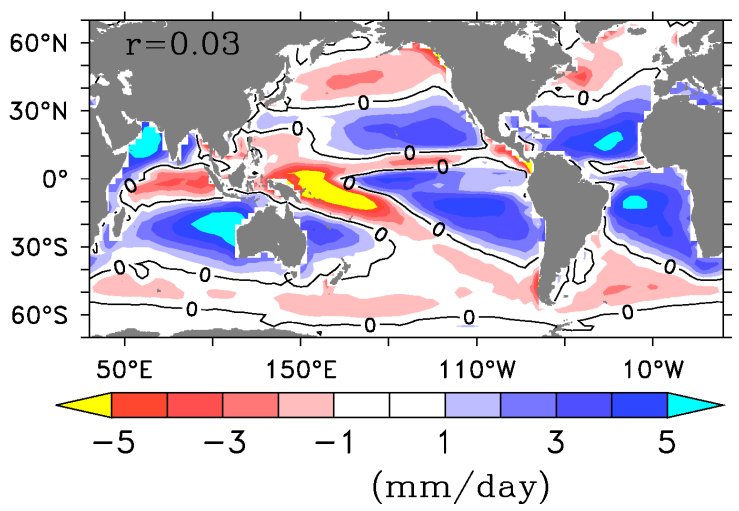

Fig 10: ACCESS-KPP annual mean fields (same as in Fig 4). Spatial correlation (r) between the forcing variable and the annual mean MLD (in Fig 12a) is shown at the top left corner of the corresponding subplot. 
(a) NHF Seasonal cycle

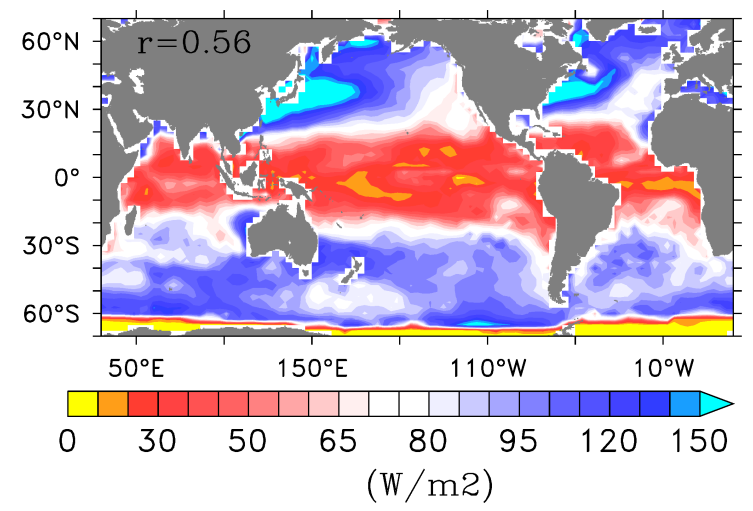

(c)Seasonal cycle of Density gradient

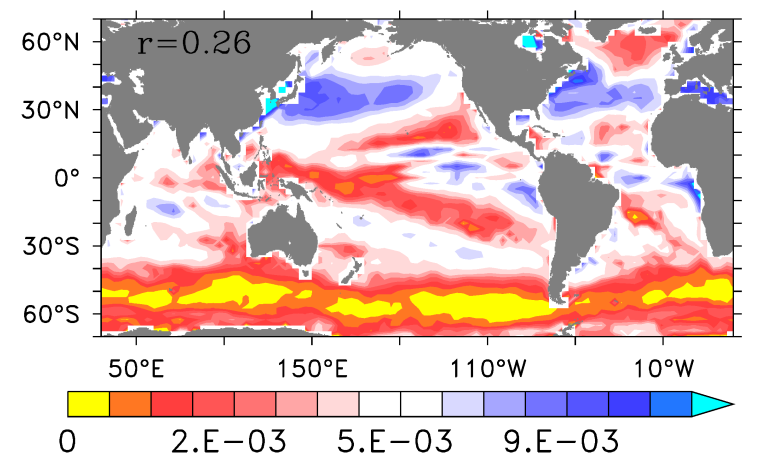

(b) Seasonal cycle of Wind-stress

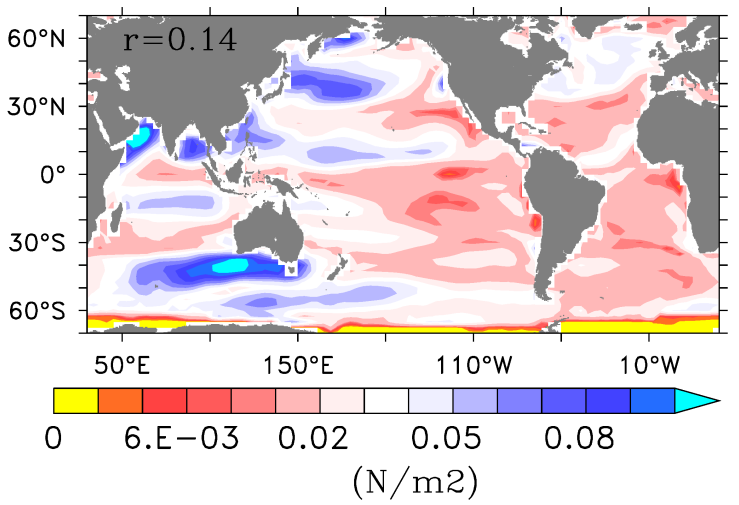

(d) Seasonal cycle of $E-P$

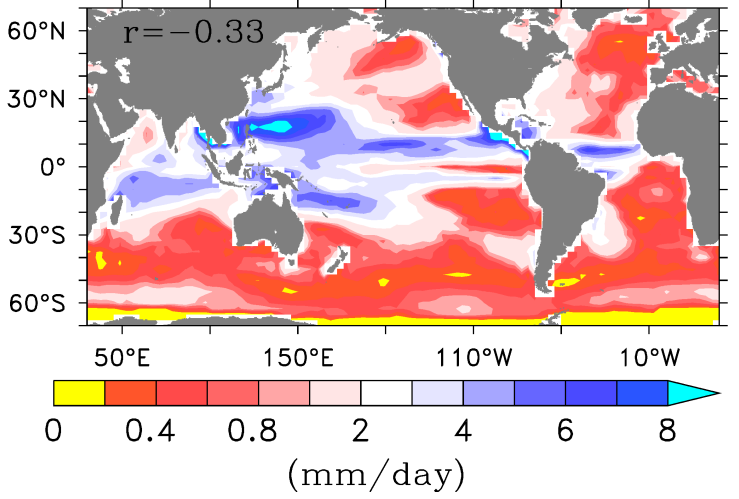

Fig 11: Seasonal amplitude of ACCESS-KPP forcing variables (same as in Fig 5). Spatial correlation (r) between the seasonal change of the forcing variable and the MLD (relative to the annual mean as in Fig 12b) is shown at the top left corner of the corresponding figure. 
(a) Annual Mean MLD

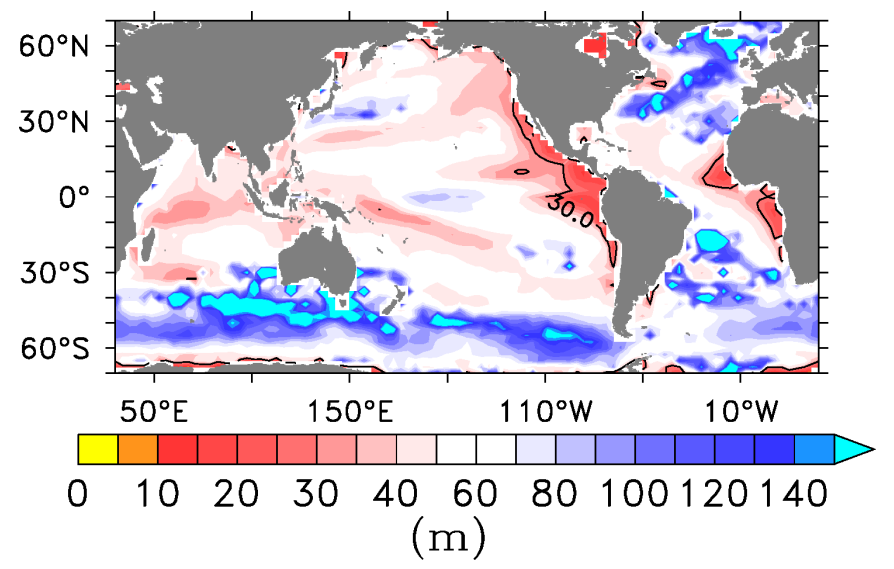

(b) Seasonal amplitude / Mean MLD

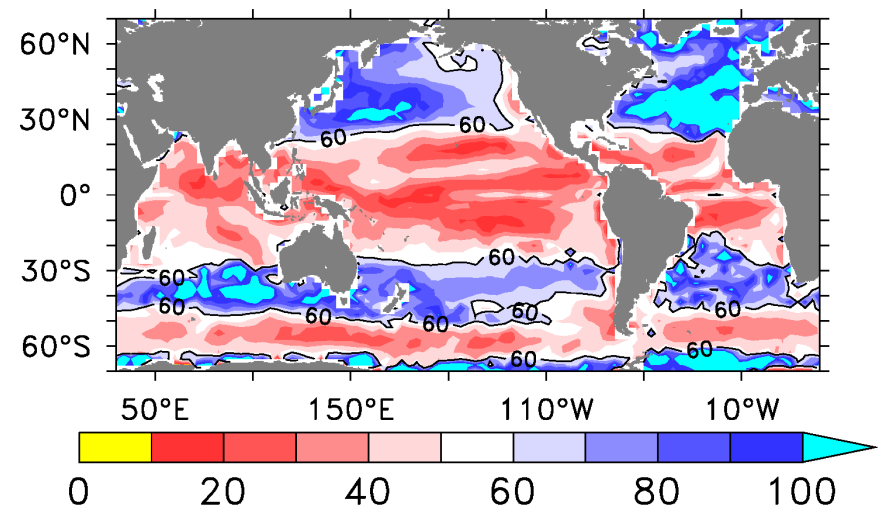

$(\%)$

Fig 12: (a) Annual mean MLD estimated from ACCESS-KPP simulated density profiles (30m contour represents the shallow mixed layer), and (b) Seasonal amplitude of MLD relative to the annual mean MLD, with contour of $60 \%$ variability (similar to Fig 2 ). 
(a) Extra-tropical-seasonal

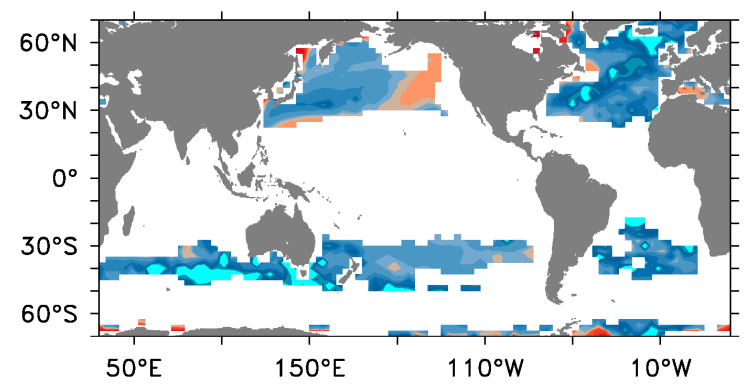

(b) Constant-deep

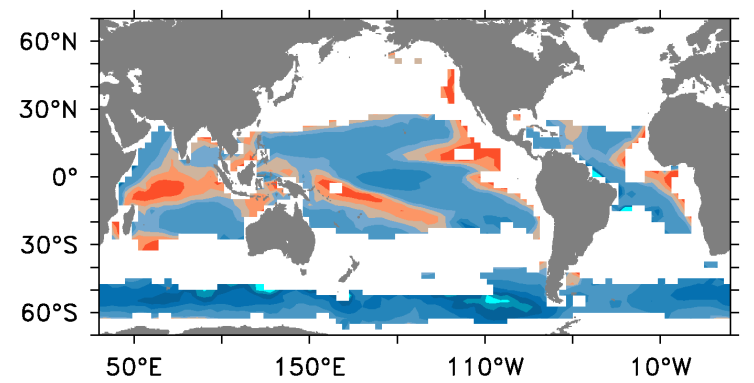

(c) Constant-shallow

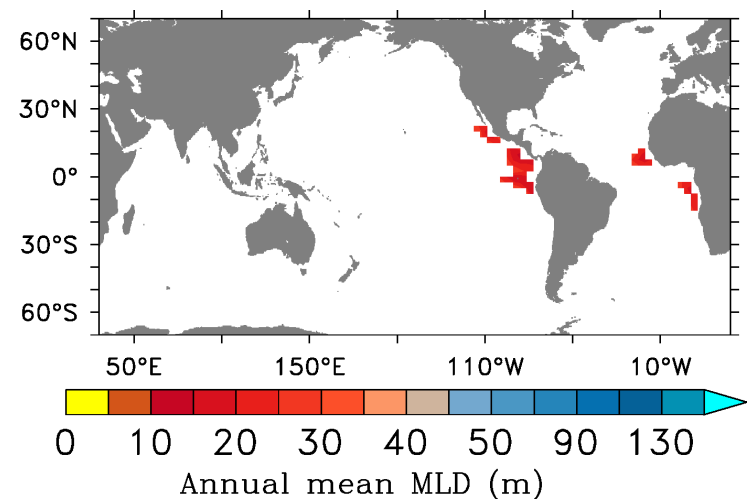

Fig 13: Different MLD regimes based on ACCESS-KPP simulation (same as in Fig 3) 
In-Phase Correlation

(a)

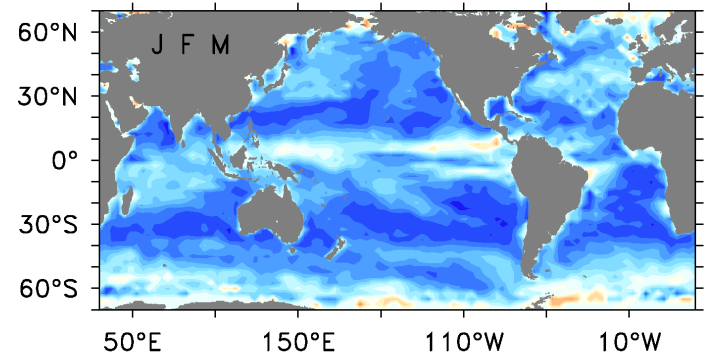

(c)

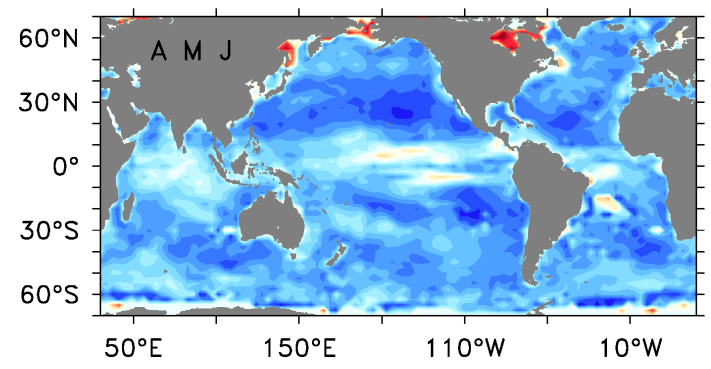

(e)

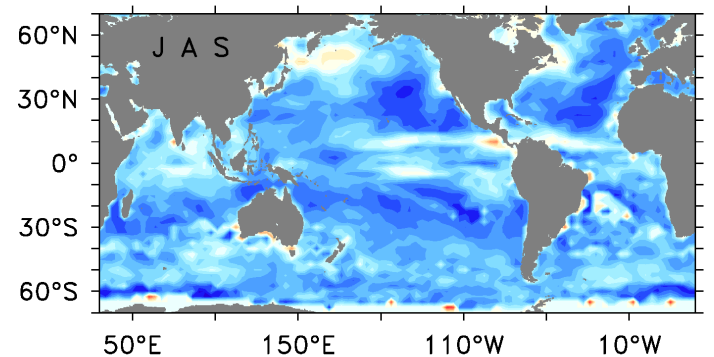

(g)

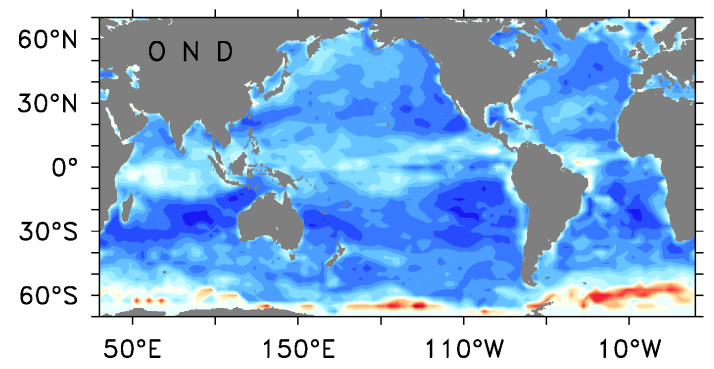

MLD Lag 1 month

(b)

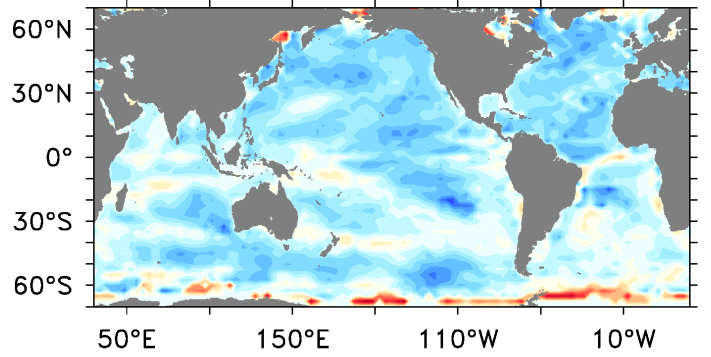

(d)

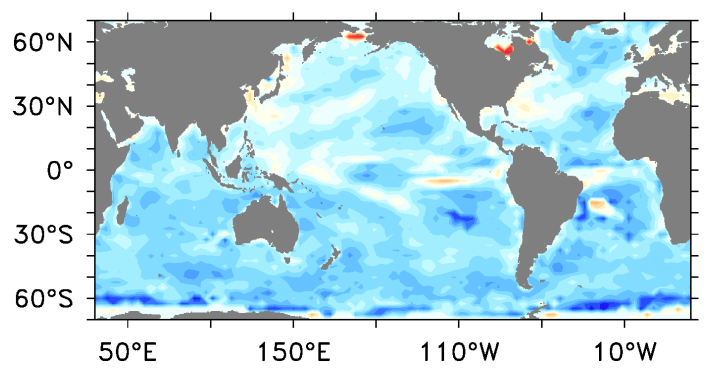

(f)

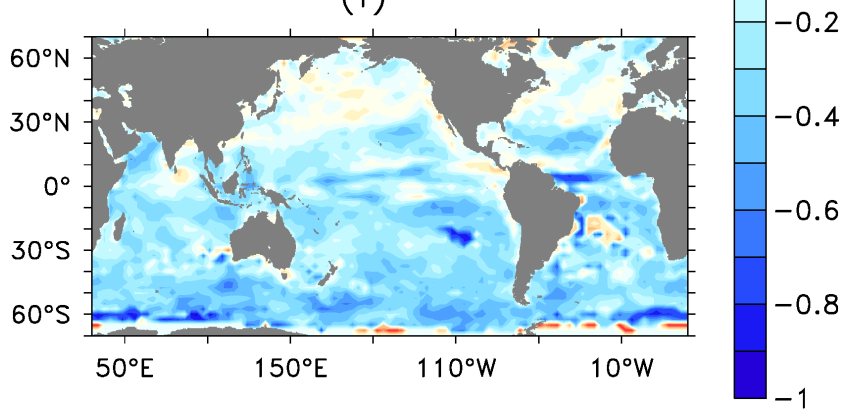

(h)

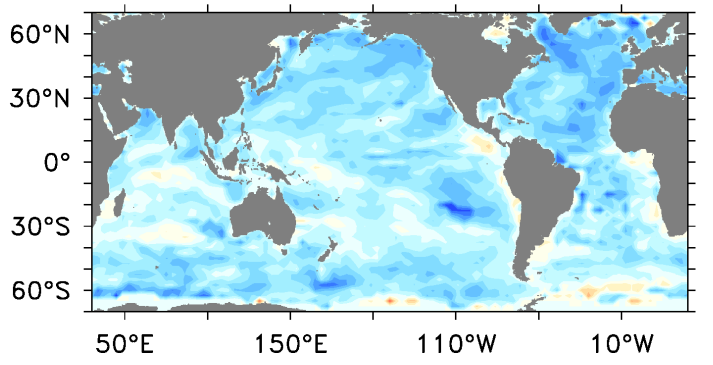

Fig 14: Cross correlation of net heat flux (NHF) and MLD anomalies in different seasons as in Fig 7 but for the ACCESS-KPP model. Significant (95\%) non-zero correlation value is \pm 0.1 . 
In-Phase Correlation

(a)

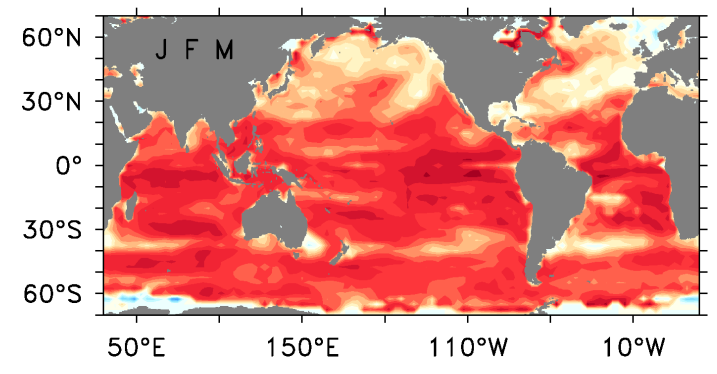

(c)

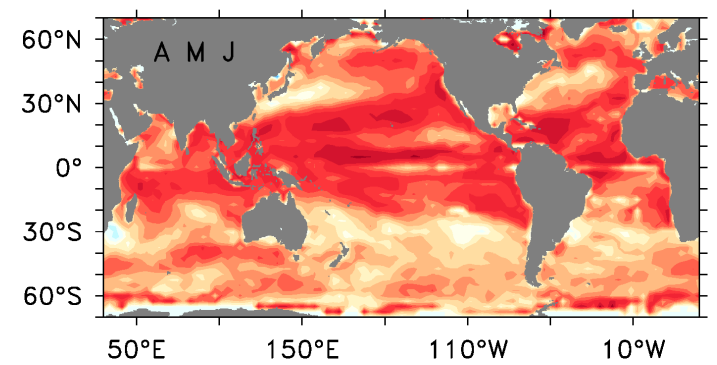

(e)

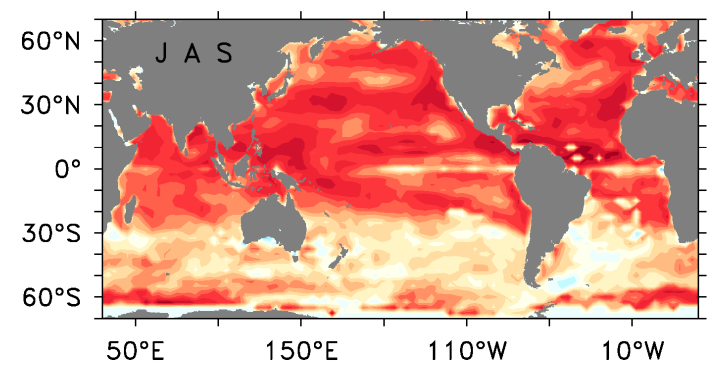

(g)

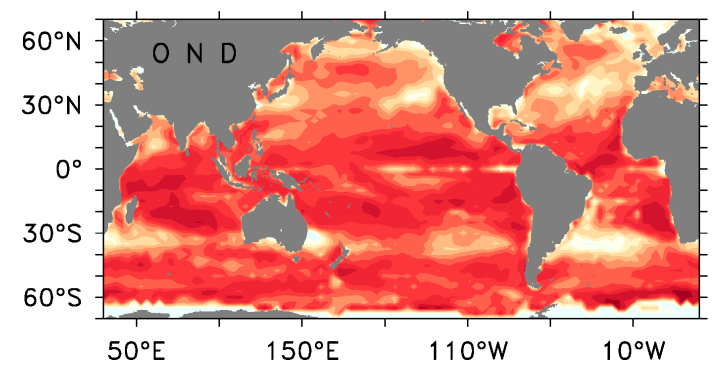

MLD Lag 1 month

(b)

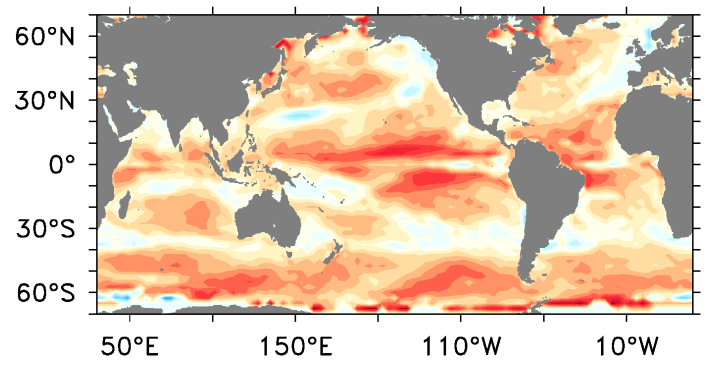

(d)

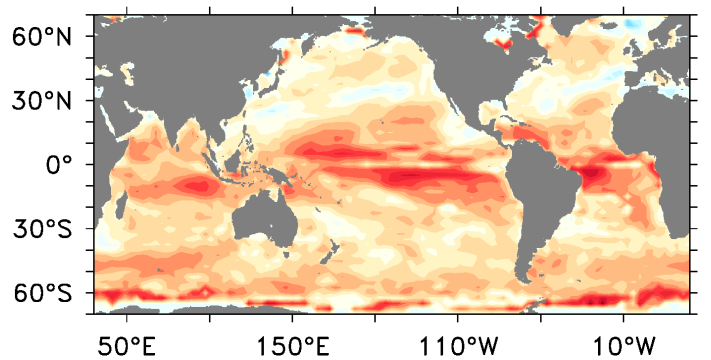

(f)

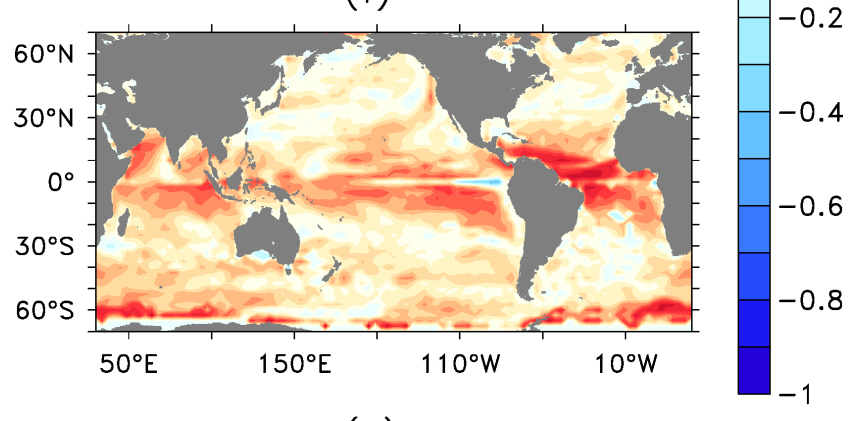

(h)

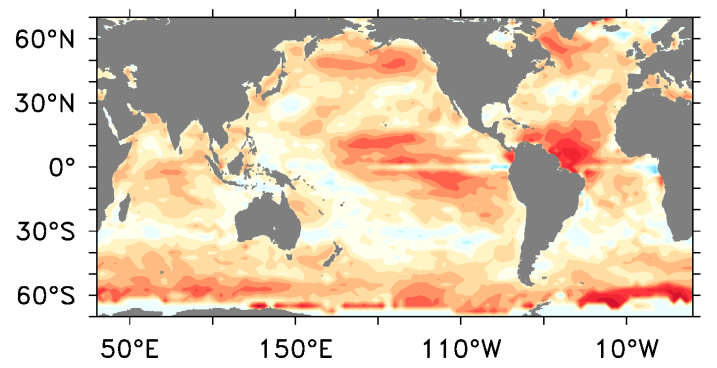

Fig 15: Cross correlation of wind-stress (TAU) and MLD anomalies in different seasons as in Fig 8 but for the ACCESS-KPP model. Significant (95\%) non-zero correlation value is \pm 0.1 . 


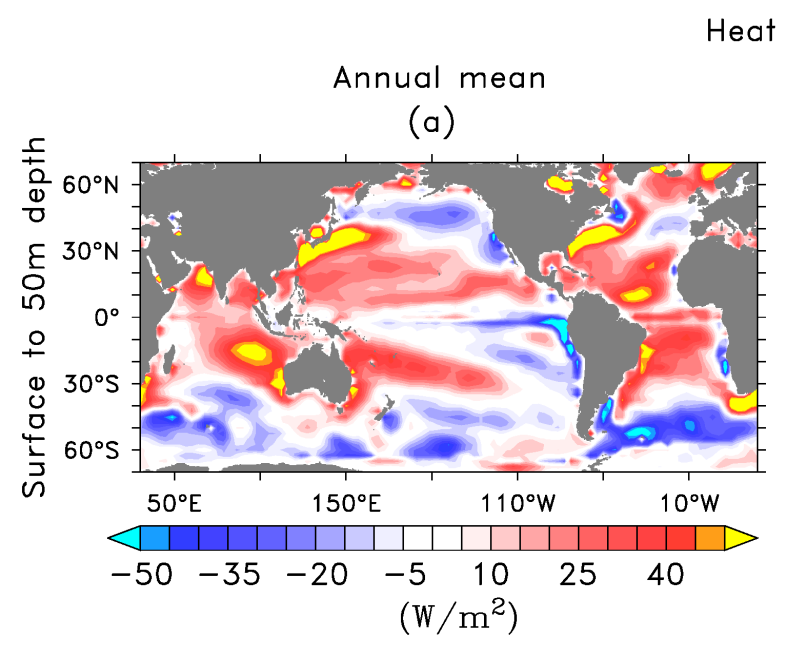

(b)

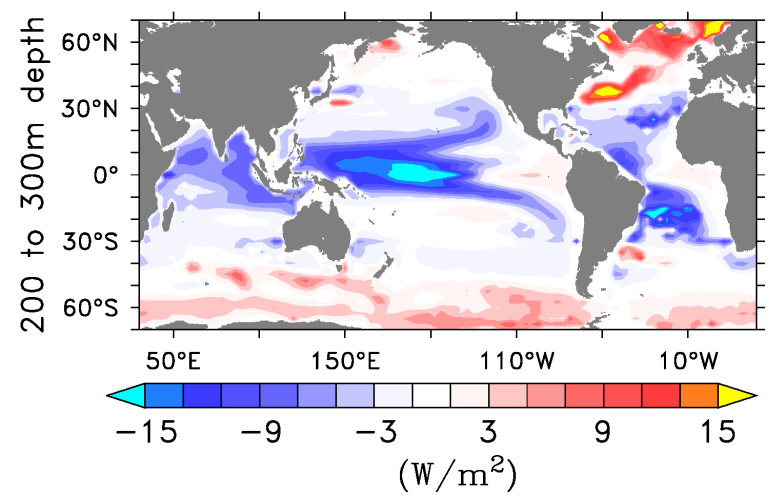

Seasonal cycle

(c)

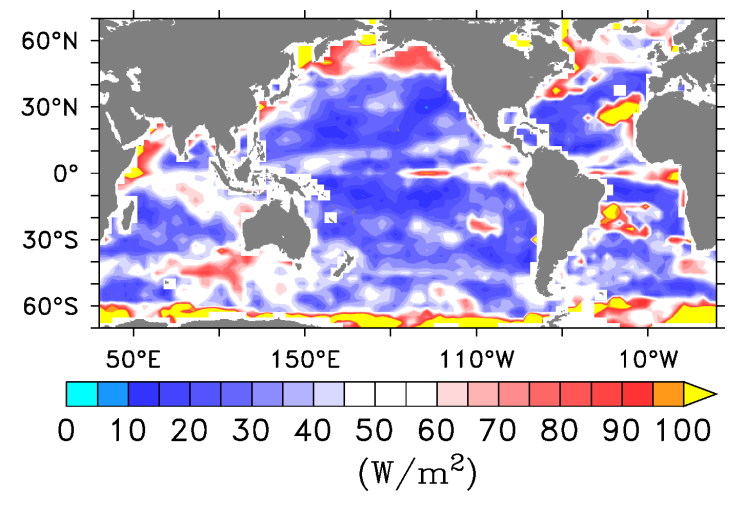

(d)

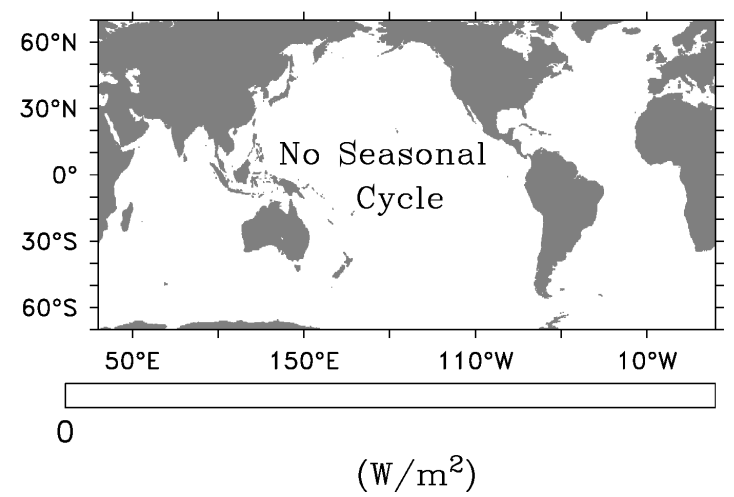

Fig 16: Annual mean $(a, b)$ and seasonal cycle $(c, d)$ of heat flux correction applied on the model levels (top) surface to $50 \mathrm{~m}$, and (bottom) $200-300 \mathrm{~m}$ depth. The actual flux correction at each model level is in $\mathrm{W} / \mathrm{m}^{3}$ and here we multiplied with the thickness of all the layers (50m and $100 \mathrm{~m}$, respectively) to show the values in units of $\mathrm{W} / \mathrm{m}^{2}$. Seasonal cycle corresponds to the standard deviation of monthly flux correction in $\mathrm{W} / \mathrm{m}^{2}$. The deeper levels have no seasonal cycle corrections. 


\section{Supplementary figures}

In-Phase Correlation

(a)

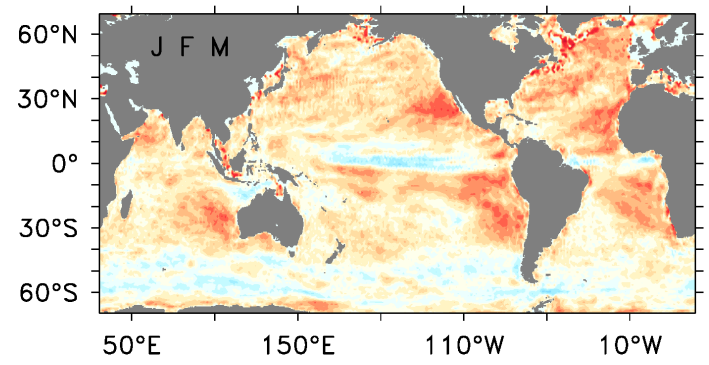

(c)

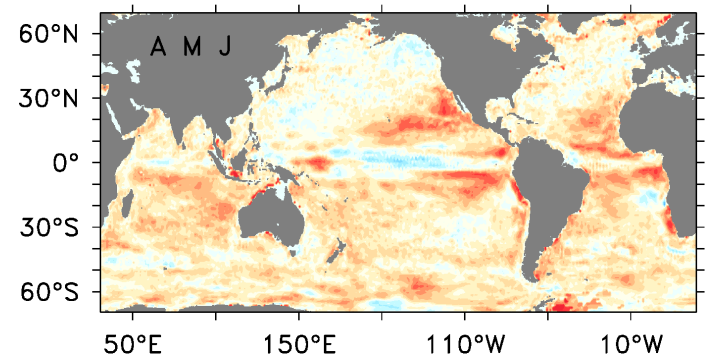

(e)

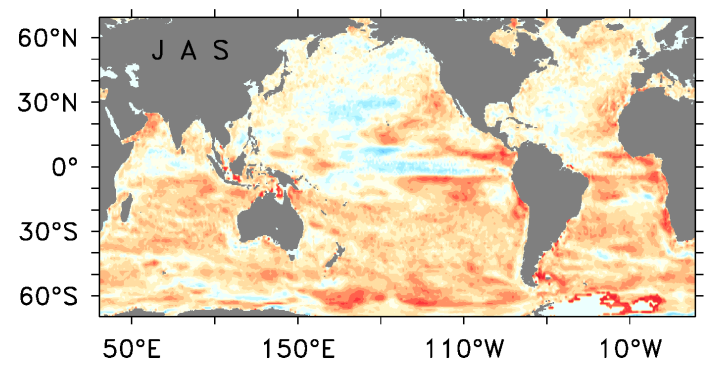

(g)

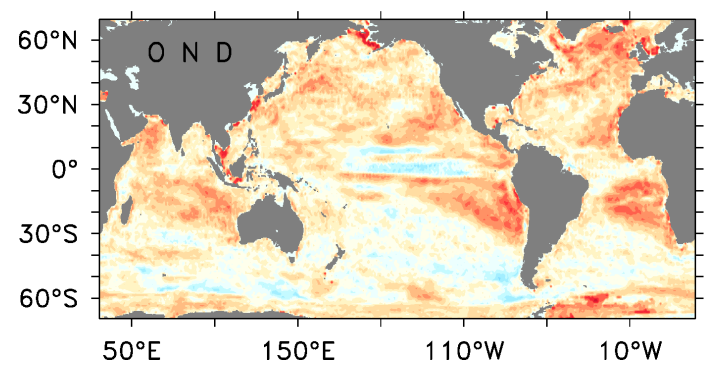

MLD Lag 1 month

(b)

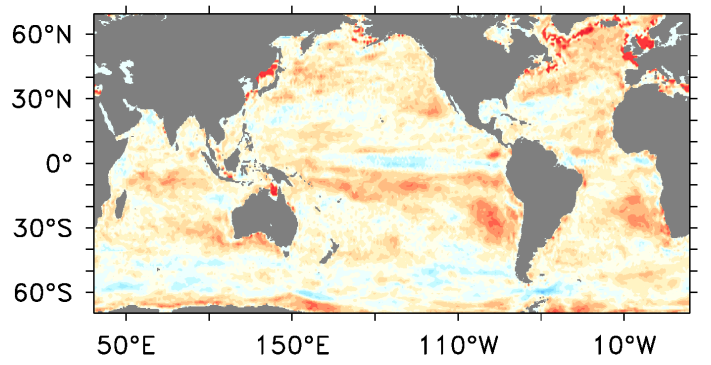

(d)

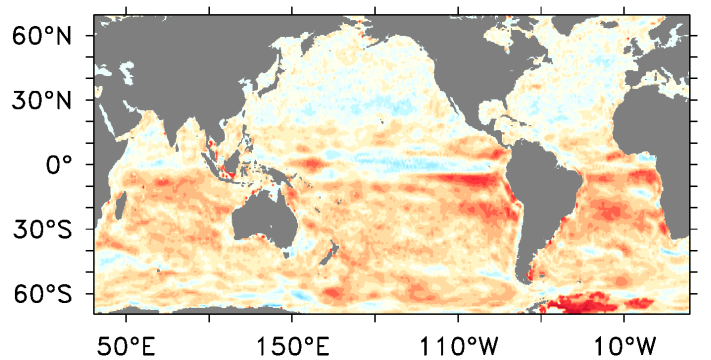

(f)

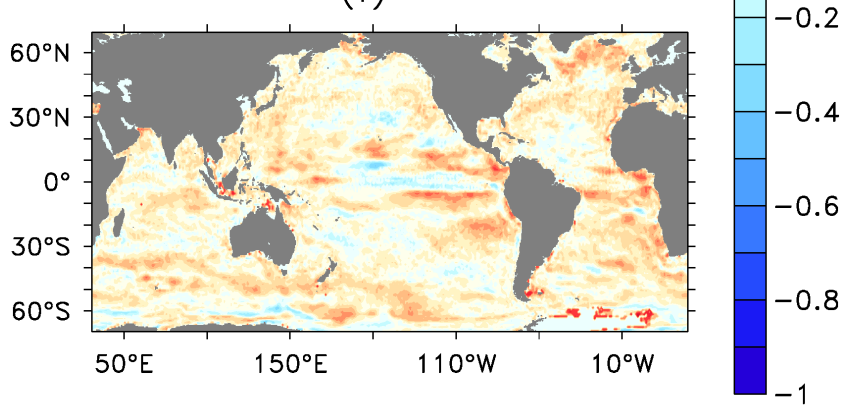

(h)

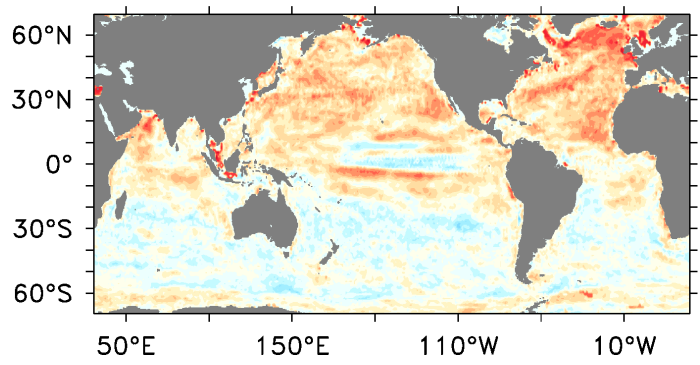

SFig 1: Cross correlation of E-P and MLD anomalies in different seasons from GECCO2.

Left column shows concurrent correlations and the right column represents the corresponding one-month lag correlations, where MLD lags the forcing by one month. The rows represent from top to bottom the different seasons: January-March (JFM), April-June (AMJ), JulySeptember (JAS), and October-November (OND). Significant (95\%) non-zero correlation value is \pm 0.1 . 
In-Phase Correlation

(a)

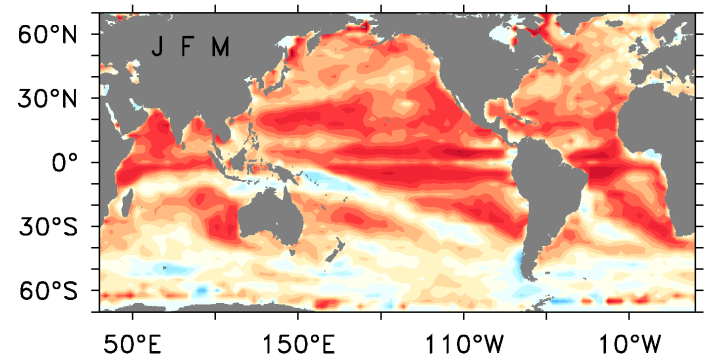

(c)

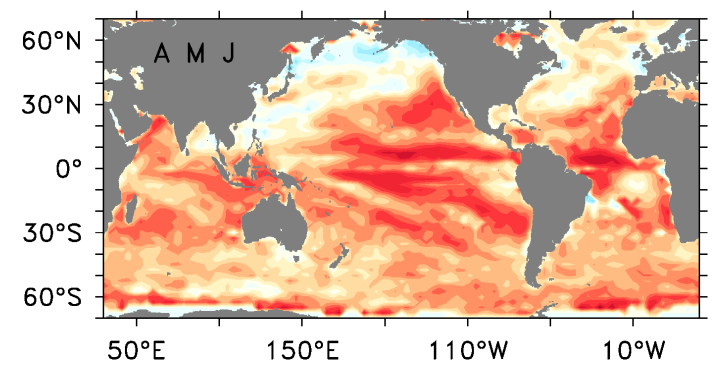

(e)

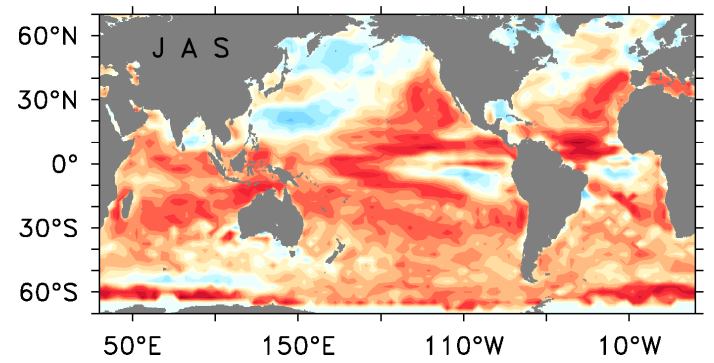

(g)

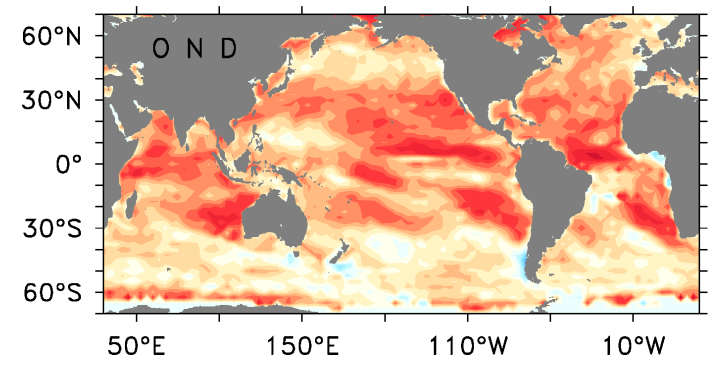

MLD Lag 1 month

(b)

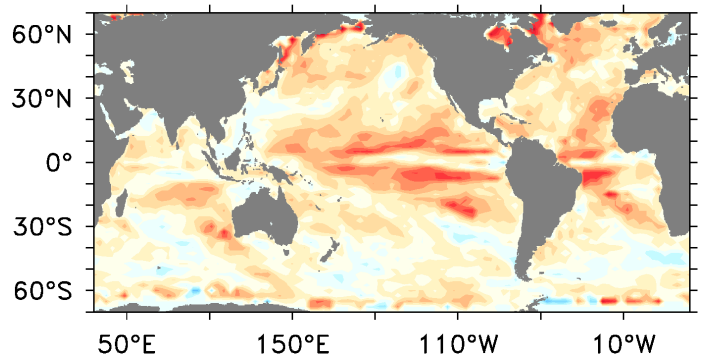

(d)

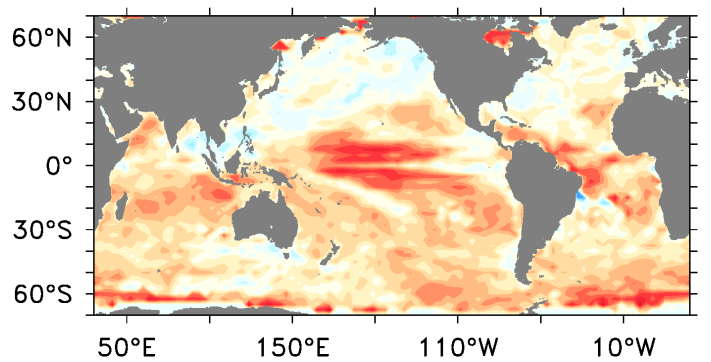

(f)

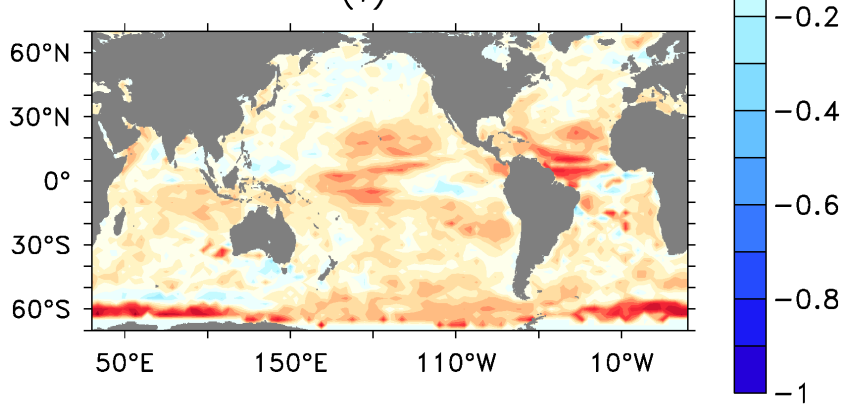

(h)

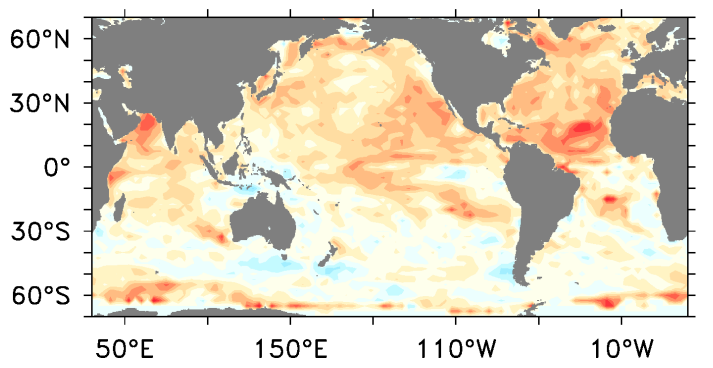

SFig 2: Cross correlation of E-P and MLD anomalies as in SFig 1 but for the ACCESS-KPP coupled model. Significant (95\%) non-zero correlation value is \pm 0.1 . 
Table 1: Spatial correlation of variables in model and reanalyses data. The hyphen represents missing or no data.

\begin{tabular}{|c|c|c|c|c|}
\hline \multicolumn{2}{|c|}{ ACCESS-KPP } & GECCO2 & $\begin{array}{c}\text { NCEP- } \\
\text { GODAS }\end{array}$ & SODA \\
\hline \multirow{2}{*}{ MLD } & Mean & 0.61 & 0.44 & 0.62 \\
\cline { 2 - 5 } & Seasonal Cycle & 0.57 & 0.44 & 0.58 \\
\hline \multirow{2}{*}{ NHF } & Mean & 0.71 & 0.68 & - \\
\cline { 2 - 5 } & Seasonal Cycle & 0.86 & 0.84 & - \\
\hline \multirow{2}{*}{ TAU } & Mean & 0.72 & 0.83 & 0.84 \\
\cline { 2 - 5 } & Seasonal Cycle & 0.53 & 0.54 & 0.62 \\
\hline \multirow{2}{*}{ E-P } & Mean & 0.65 & 0.83 & - \\
\cline { 2 - 5 } & Seasonal Cycle & 0.31 & 0.79 & - \\
\hline
\end{tabular}

Table 2: Spatial correlation of variables in GECCO2 and other reanalyses. (The values in brackets are the spatial correlation of GODAS and SODA data). The hyphen represents missing or no data.

\begin{tabular}{|c|c|c|c|}
\hline \multicolumn{2}{|c|}{ GECCO2 } & $\begin{array}{c}\text { NCEP- } \\
\text { GODAS }\end{array}$ & SODA \\
\hline \multirow{2}{*}{ MLD } & Mean & 0.50 & $0.71(0.57)$ \\
\cline { 2 - 4 } & Seasonal Cycle & 0.54 & $0.72(0.62)$ \\
\hline \multirow{2}{*}{ NHF } & Mean & 0.75 & - \\
\cline { 2 - 4 } & Seasonal Cycle & 0.94 & - \\
\hline \multirow{2}{*}{ TAU } & Mean & 0.82 & $0.83(0.96)$ \\
\cline { 2 - 4 } & Seasonal Cycle & 0.65 & $0.80(0.82)$ \\
\hline \multirow{2}{*}{ E-P } & Mean & 0.76 & - \\
\cline { 2 - 4 } & Seasonal Cycle & 0.39 & - \\
\hline
\end{tabular}

